\title{
Cloud condensation nuclei in pristine tropical rainforest air of Amazonia: size-resolved measurements and modeling of atmospheric aerosol composition and CCN activity
}

\author{
S. S. Gunthe ${ }^{1}$, S. M. King ${ }^{2}$, D. Rose ${ }^{1}$, Q. Chen ${ }^{2}$, P. Roldin ${ }^{3}$, D. K. Farmer ${ }^{4}$, J. L. Jimenez ${ }^{4}$, P. Artaxo ${ }^{5}$, M. O. Andreae ${ }^{1}$, \\ S. T. Martin ${ }^{2}$, and U. Pöschl ${ }^{1}$ \\ ${ }^{1}$ Max Planck Institute for Chemistry, Biogeochemistry Department, Mainz, Germany \\ ${ }^{2}$ Harvard University, School of Engineering and Applied Sciences \& Department of Earth and Planetary Sciences, \\ Cambridge, MA, USA \\ ${ }^{3}$ Lund University, Nuclear Physics, Faculty of Technology, Lund, Sweden \\ ${ }^{4}$ University of Colorado, Dept. of Chemistry \& Biochemistry and CIRES, Boulder, CO, USA \\ ${ }^{5}$ Instituto de Fisica, Universidade de Sao Paulo, Sao Paulo, Brazil
}

Received: 12 December 2008 - Published in Atmos. Chem. Phys. Discuss.: 4 February 2009

Revised: 7 August 2009 - Accepted: 10 September 2009 - Published: 9 October 2009

\begin{abstract}
Atmospheric aerosol particles serving as cloud condensation nuclei $(\mathrm{CCN})$ are key elements of the hydrological cycle and climate. We have measured and characterized $\mathrm{CCN}$ at water vapor supersaturations in the range of $S=0.10-0.82 \%$ in pristine tropical rainforest air during the AMAZE-08 campaign in central Amazonia.

The effective hygroscopicity parameters describing the influence of chemical composition on the $\mathrm{CCN}$ activity of aerosol particles varied in the range of $\kappa \approx 0.1-0.4$ $(0.16 \pm 0.06$ arithmetic mean and standard deviation). The overall median value of $\kappa \approx 0.15$ was by a factor of two lower than the values typically observed for continental aerosols in other regions of the world. Aitken mode particles were less hygroscopic than accumulation mode particles $(\kappa \approx 0.1$ at $D \approx 50 \mathrm{~nm} ; \kappa \approx 0.2$ at $D \approx 200 \mathrm{~nm}$ ), which is in agreement with earlier hygroscopicity tandem differential mobility analyzer (H-TDMA) studies.

The CCN measurement results are consistent with aerosol mass spectrometry (AMS) data, showing that the organic mass fraction $\left(f_{\text {org }}\right)$ was on average as high as $\sim 90 \%$ in the Aitken mode $(D \leq 100 \mathrm{~nm})$ and decreased with increasing particle diameter in the accumulation mode $(\sim 80 \%$ at $D \approx 200 \mathrm{~nm}$ ). The $\kappa$ values exhibited a negative linear cor-
\end{abstract}

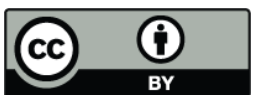

Correspondence to: S. S. Gunthe (gunthe@mpch-mainz.mpg.de) relation with $f_{\text {org }}\left(R^{2}=0.81\right)$, and extrapolation yielded the following effective hygroscopicity parameters for organic and inorganic particle components: $\kappa_{\text {org }} \approx 0.1$ which can be regarded as the effective hygroscopicity of biogenic secondary organic aerosol (SOA) and $\kappa_{\text {inorg }} \approx 0.6$ which is characteristic for ammonium sulfate and related salts. Both the size dependence and the temporal variability of effective particle hygroscopicity could be parameterized as a function of AMS-based organic and inorganic mass fractions $\left(\kappa_{p}=\kappa_{\text {org }} \times f_{\text {org }}+\kappa_{\text {inorg }} \times f_{\text {inorg }}\right)$. The CCN number concentrations predicted with $\kappa_{p}$ were in fair agreement with the measurement results $(\sim 20 \%$ average deviation). The median CCN number concentrations at $S=0.1-0.82 \%$ ranged from $N_{\mathrm{CCN}, 0.10} \approx 35 \mathrm{~cm}^{-3}$ to $N_{\mathrm{CCN}, 0.82} \approx 160 \mathrm{~cm}^{-3}$, the median concentration of aerosol particles larger than $30 \mathrm{~nm}$ was $N_{\mathrm{CN}, 30} \approx 200 \mathrm{~cm}^{-3}$, and the corresponding integral CCN efficiencies were in the range of $N_{\mathrm{CCN}, 0.10} / N_{\mathrm{CN}, 30} \approx 0.1$ to $N_{\mathrm{CCN}, 0.82} / N_{\mathrm{CN}, 30} \approx 0.8$.

Although the number concentrations and hygroscopicity parameters were much lower in pristine rainforest air, the integral CCN efficiencies observed were similar to those in highly polluted megacity air. Moreover, model calculations of $N_{\mathrm{CCN}, S}$ assuming an approximate global average value of $\kappa \approx 0.3$ for continental aerosols led to systematic overpredictions, but the average deviations exceeded $\sim 50 \%$ only at low water vapor supersaturation $(0.1 \%)$ and low particle number concentrations $\left(\leq 100 \mathrm{~cm}^{-3}\right)$. Model calculations assuming a

Published by Copernicus Publications on behalf of the European Geosciences Union. 
constant aerosol size distribution led to higher average deviations at all investigated levels of supersaturation: $\sim 60 \%$ for the campaign average distribution and $\sim 1600 \%$ for a generic remote continental size distribution. These findings confirm earlier studies suggesting that aerosol particle number and size are the major predictors for the variability of the $\mathrm{CCN}$ concentration in continental boundary layer air, followed by particle composition and hygroscopicity as relatively minor modulators.

Depending on the required and applicable level of detail, the information and parameterizations presented in this paper should enable efficient description of the $\mathrm{CCN}$ properties of pristine tropical rainforest aerosols of Amazonia in detailed process models as well as in large-scale atmospheric and climate models.

\section{Introduction}

Cloud condensation nuclei $(\mathrm{CCN})$ are the subset of atmospheric aerosol particles that enable the condensation of water vapor and formation of cloud droplets at a given level of water vapor supersaturation. They are key elements of the hydrological cycle and climate on regional as well as global scales. Elevated concentrations of $\mathrm{CCN}$ tend to increase the concentration and decrease the size of droplets in cloud. Apart from the indirect effect on radiative forcing, this may lead to the suppression of precipitation in shallow and short-lived clouds but also to greater convective overturning and more precipitation in deep convective clouds (Rosenfeld et al., 2008). The response of cloud characteristics and precipitation processes to increasing anthropogenic aerosol concentrations represents one of the largest uncertainties in the current understanding of climate change. One of the crucial challenges is to characterize the hygroscopicity and $\mathrm{CCN}$ activity of aerosol particles, i.e. their ability to take up water vapor and form cloud droplets under relevant atmospheric conditions (e.g. McFiggans et al., 2006; IAPSAG, 2007; IPCC, 2007; Andreae and Rosenfeld, 2008).

During the dry season, the properties and effects of atmospheric aerosols over Amazonia are often strongly influenced by anthropogenic biomass burning emissions (Artaxo et al., 1998, 2002; Andreae et al., 2004; Martin et al., 2009a; and references therein). During the wet season, however, Amazonia is one of the few continental regions on Earth where the aerosol composition is not dominated by anthropogenic sources, and where aerosol particle properties, interactions and effects can be studied under nearly natural background conditions (Artaxo et al., 1990; Talbot et al., 1990; Andreae, 2007; Martin et al., 2009a, and references therein).

Several studies have investigated the hygroscopicity of Amazonian aerosols by hygroscopicity tandem differential mobility analyzer (HTDMA) experiments, i.e. by the determination of particle growth factors at relative humidities be- low $100 \%$, which can be extrapolated to predict the CCN activity under supersaturated conditions (Zhou et al., 2002; Rissler et al., 2004, 2006; Vestin et al., 2007). Some studies have also applied CCN counters (CCNC) to directly measure $\mathrm{CCN}$ concentrations at various levels of water vapor supersaturation (Roberts et al., 2001, 2002, 2003; Andreae et al., 2004; Rissler et al., 2004; Vestin et al., 2007; Freud et al., 2008, Martins et al., 2009). Zhou et al. (2002), Rissler et al. (2006), and Vestin et al. (2007) have reported HTDMA and CCNC measurement results from the Amazonian wet season, which will be discussed below. So far, however, no size-resolved CCN measurements have been reported from Amazonia.

In the "Amazonian Aerosol Characterization Experiment2008" (AMAZE-08) during the wet season in FebruaryMarch 2008 (Martin et al., 2009b), we have used a continuous-flow CCN counter (DMT-CCNC) in combination with an aerosol mass spectrometer (AMS) to characterize the $\mathrm{CCN}$ efficiency and chemical composition of pristine tropical rainforest aerosols as a function of dry particle diameter and water vapor supersaturation. To our knowledge, such information has not been reported before. In this manuscript we present the measurement data, as well as model formalisms and parameters that enable efficient description of the observed CCN properties. Moreover, we compare the results to earlier investigations of the $\mathrm{CCN}$ activity of atmospheric aerosol particles in Amazonia and other continental regions.

\section{Methods}

\subsection{Measurement site and meteorological conditions}

The measurements were carried out over the period of 14 February to 12 March 2008, i.e. during the Amazonian wet season, at a remote site in the rainforest $60 \mathrm{~km}$ of NNW of the city of Manaus in Brazil (2.594541 S, 60.209289 W, $110 \mathrm{~m}$ above sea level). The observational tower (TT34) was located in the Reserva Biologica do Cuieiras and managed by the Instituto Nacional de Pesquisas da Amazonia (INPA) and the Large-Scale Biosphere-Atmosphere Experiment in Amazonia (LBA). As illustrated in Fig. 1, the air masses came mainly from the NE across $1600 \mathrm{~km}$ of almost untouched forest, allowing the study of pristine tropical rainforest conditions. The average meteorological parameters (arithmetic mean \pm standard deviation) recorded during the $\mathrm{CCN}$ measurement period at the aerosol inlet on top of TT34 were: $(297 \pm 2) \mathrm{K}$ ambient temperature, $(92 \pm 10)$ $\%$ ambient relative humidity (RH), $(995 \pm 5) \mathrm{hPa}$ ambient pressure, $(1.2 \pm 0.7) \mathrm{m} \mathrm{s}^{-1}$ local wind speed, and $51.5^{\circ}$ local wind direction (vector mean weighted by wind speed). Rain events occurred on most days of the campaign; the median daily amount of precipitation was higher during the focus period at the end of the campaign $\left(\sim 17 \mathrm{~mm} \mathrm{~d}^{-1} ; 6-\right.$ 12 March 2008, Sect. 3.1.2) than during the rest of the 


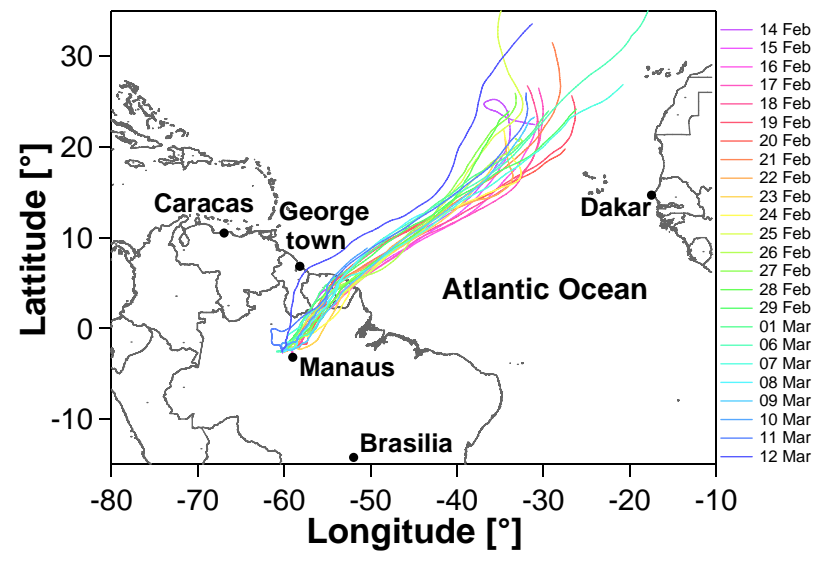

Fig. 1. Location of the AMAZE-08 measurement site in central Amazonia (2.594541 S, $60.209289 \mathrm{~W}), 60 \mathrm{~km}$ NNW of Manaus, Brazil, with 9 day back trajectories (HYSPLIT, NOAA-ARL, GDAS1 model, start height $50 \mathrm{~m}$, start time 23:00 UTC) illustrating the large scale airflow during the $\mathrm{CCN}$ measurement period (14 February-12 March 2008).

campaign $\left(\sim 9 \mathrm{~mm} \mathrm{~d}^{-1}\right)$. For more information about the measurement location and meteorological conditions see Martin et al., 2009b.

Aerosols from above the forest canopy were sampled through an inlet at the top of TT34 (38.75 m above ground, Rupprecht \& Patashnick PM10, 20 L $\mathrm{min}^{-1}$ flow rate) via a stainless steel line (19.05 mm o.d.) to the measurement container at the base of the tower. Before entering the container, the sample flow passed through a diffusion dryer with silica gel/molecular sieve cartridges (alternating regeneration with dry pressurized air, regeneration cycles 15-50 min, average $\mathrm{RH}=(33 \pm 7) \%$. After drying, the sample flow was split by a manifold and fed into a wide range of aerosol and trace gas measurement instruments. One of the lines led to the CCN measurement setup described below (stainless steel, $6.35 \mathrm{~mm}$ o.d., $3 \mathrm{~m}$ length, $1.5 \mathrm{~L} \mathrm{~min}^{-1}$ flow rate). For more information about the sampling system and instrumentation of AMAZE-08 see Martin et al. (2009b).

\subsection{CCN measurement and data analysis}

Size resolved CCN efficiency spectra (activation curves) were measured with a Droplet Measurement Technologies continuous flow CCN counter (DMT-CCNC, Roberts and Nenes, 2005; Lance et al., 2006) coupled to a Differential Mobility Analyzer (DMA; TSI 3071; sheath flow $10 \mathrm{~L} \mathrm{~min}^{-1}$ ) and a condensation particle counter (CPC; TSI 3762; sample flow 1.0 $\mathrm{L} \mathrm{min}^{-1}$; Frank et al., 2006; Rose et al., 2008a). The CCNC was operated at a total flow rate of $0.5 \mathrm{~L} \mathrm{~min}^{-1}$ with a sheath-to-aerosol flow ratio of 10 .

The temperature, pressure and relative humidity at the

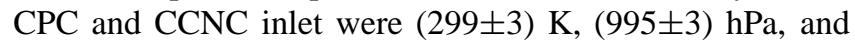

$(30 \pm 5) \%$ respectively (arithmetic mean \pm standard deviation). For compliance with AMAZE-08 standardization guidelines, the concentration values measured under the above conditions have been normalized to the volume that the sampled air would occupy under dry standard conditions (STP: $273 \mathrm{~K}, 1000 \mathrm{hPa}, 0 \% \mathrm{RH}$ ). Based on the ideal gas law, the normalization was performed by multiplying the measured concentration values with a factor of 1.1. Note, however, that the performed STP correction refers only to the sampled gas volume but does not account for changes in gasparticle partitioning and corresponding changes in particle size and mass that are likely to result from a change in temperature and humidity and might be more substantial than the ideal gas law correction.

The effective water vapor supersaturation $(S)$ was regulated by the temperature difference between the upper and lower end of the CCNC flow column $(\Delta T)$ and calibrated with ammonium sulfate as described by Rose et al. (2008a, b); Köhler model AP3; calibration line $S=k_{S} \Delta T+S_{0}$ with $k_{S}=0.0789 \% \mathrm{~K}^{-1}, S_{0}=-0.0909 \%, R^{2}=0.9985$; relative uncertainty $\Delta S / S<10 \%$ ).

For each CCN measurement cycle, $\Delta T$ was set to 5 different levels $(2.4-11.5 \mathrm{~K})$ corresponding to $S$ values in the range of $0.10-0.82 \%$. The temperature of the optical particle counter in the $\mathrm{CCNC}$ was $2 \mathrm{~K}$ higher than the temperature at the lower end of the CCNC column. For each $\Delta T$ and $S$, respectively, the diameter of the dry aerosol particles selected by the DMA $(D)$ was set to 9 different values in the range of 20-290 nm depending on the supersaturation selected. At each $D$, the number concentration of total aerosol particles (condensation nuclei, $\mathrm{CN}$ ), $N_{\mathrm{CN}}$, was measured with the $\mathrm{CPC}$, and the number concentration of $\mathrm{CCN}$, $N_{\mathrm{CCN}}$, was measured with the CCNC. The integration time for each measurement data point was $160 \mathrm{~s}$, the recording of a $\mathrm{CCN}$ efficiency spectrum $\left(N_{\mathrm{CCN}} / N_{\mathrm{CN}}\right.$ vs. $\left.D\right)$ took $\sim 35 \mathrm{~min}$, and the completion of a full measurement cycle comprising CCN efficiency spectra at 5 different supersaturation levels took $\sim 180 \mathrm{~min}$ (including $5 \mathrm{~min}$ of settling time for the changeover from highest to lowest $S$ ). 169 measurement cycles were performed during the AMAZE-08 campaign from 14 February until 12 March 2008, with occasional short term interruptions for instrument calibration and maintenance, and with a four day break due to a power outage and subsequent repair work (2-6 March). Note that for the lowest supersaturation level applied in the atmospheric measurements, the exact mean value $S=0.095 \%$ was used for the calculations outlined below, but for simplicity a rounded value of $0.10 \%$ is listed in figures and tables.

The measurement data of the CCN efficiency spectra were corrected for the effects of multiply charged particles, differences in the CCNC and CPC counting efficiencies with a constant correction factor $f_{\text {corr }}=1.05$, and the DMA transfer function as described by Rose et al. (2008a, b). For the multiple charge correction, we used the total aerosol particle number size distributions that were derived from the 
CPC measurement data and averaged over each full $\mathrm{CCN}$ measurement cycle as described below. The uncertainties of $N_{\mathrm{CCN}}, N_{\mathrm{CN}}$ and $N_{\mathrm{CCN}} / N_{C \mathrm{~N}}$ are estimated to be $<20 \%$ for individual measurement data points and $<10 \%$ for average values and fit parameters (Rose et al., 2008a, b).

By fitting with cumulative Gaussian distribution functions (CDF), the following parameters were derived from each measured CCN efficiency spectrum (Rose et al., 2008b): the maximum activated fraction $M A F_{f}$, the midpoint activation diameter $D_{a}$, and the standard deviation $\sigma_{a}$ of 3-parameter CDF fits, as well as the midpoint activation diameter $D_{t}$ and the standard deviation $\sigma_{t}$ of 2-parameter CDF fits with $M A F_{f}$ set to 1 . Note that the CCN efficiency measured at the largest diameter of each spectrum $\left(M A F_{m}=N_{\mathrm{CCN}} / N_{\mathrm{CN}}\right.$ at $D_{\max }$ ) was generally in good agreement with $M A F_{f}$ as derived from the 3-parameter CDF fit (deviations $<10 \%$ ).

As detailed by Rose et al. (2008b) the activation diameters and standard deviations derived from the 3-parameter and 2-parameter CDF fits are not the same for CCN efficiency spectra with $M A F_{f}<1$ : the 3-parameter fit results represent the average properties of the $\mathrm{CCN}$ active aerosol particle fraction, whereas the 2-parameter fit results approximate the overall properties of the external mixture of $\mathrm{CCN}$-active and $\mathrm{CCN}$-inactive particles.

The deviation of $M A F_{f}$ from unity represents the fraction of externally mixed $\mathrm{CCN}$-inactive particles in the diameter range of $D_{a}$ to $D_{\max }$. The CDF standard deviations are general indicators for the extent of external mixing and heterogeneity of particle composition in the investigated aerosol: $\sigma_{a}$ characterizes the $\mathrm{CCN}$-active particles in the size range around $D_{a}$, and $\sigma_{t}$ is a measure for the overall heterogeneity of $\mathrm{CCN}$-active and inactive particles in the size range around $D_{t}$. Under ideal conditions, the CDF standard deviations should be zero for an internally mixed, fully monodisperse aerosol with particles of homogenous chemical composition. Even after correcting for the DMA transfer function, however, calibration aerosols composed of high-purity ammonium sulfate exhibit small non-zero $\sigma_{a}$ values that correspond to $\sim 3 \%$ of $D_{a}$ and can be attributed to heterogeneities of the water vapor supersaturation profile in the CCNC or other non-idealities such as DMA transfer function or particle shape effects. Thus, normalized CDF standard deviation or "heterogeneity parameter" values of $\sigma / D \approx 3 \%$ indicate internally mixed $\mathrm{CCN}$ whereas higher values indicate external mixtures of particles with different chemical composition and hygroscopicity, respectively (Rose et al., 2008b).

For all data pairs of supersaturation and activation diameter derived from the CCN efficiency spectra measured in this study, effective hygroscopicity parameters $\kappa$ (Petters and Kreidenweis, 2007; Pöschl et al., 2009a) were calculated using the $\kappa$-Köhler model equations and parameters specified in Rose et al. (2008b, surface tension $0.072 \mathrm{~J} \mathrm{~m}^{-2}$, temperature $298 \mathrm{~K}$ ). Note that the $\kappa$ values derived from CCN measurement data through Köhler model calculations assuming the surface tension of pure water have to be regarded as "effective hygroscopicity parameters" that account not only for the reduction of water activity by the solute ("effective Raoult parameters") but also for surface tension effects (Petters and Kreidenweis, 2007; Rose et al., 2008b; Mikhailov et al., 2009; Pöschl et al., 2009a).

The parameter $\kappa_{a}$ calculated from the data pairs of $S$ and $D_{a}$ characterizes the average hygroscopicity of CCN-active particles in the size range around $D_{a} . \kappa_{t}$ calculated from $D_{t}$ is an approximate measure (proxy) for the effective hygroscopicity of mixtures of CCN-active and -inactive particles in the size range around $D_{t}$ (Rose et al., 2008b). Accordingly, $\kappa_{t}$ is better suited for comparison with average $\kappa$ values calculated from H-TDMA data ( $\kappa_{t, \text { avg }}$, Sect. 3.1.3) and for the calculation of $\mathrm{CCN}$ number concentrations when $\mathrm{CCN}$ active particles are externally mixed with $\mathrm{CCN}$-inactive particles (Sect. 3.2.2). On the other hand, $\kappa_{a}$ is better suited for comparison with $\kappa$ values predicted from AMS measurements $\left(\kappa_{p}\right.$, Sect. 3.3), because $\kappa_{a}$ is not influenced by $\mathrm{CCN}$-inactive particles consisting mostly of insoluble and refractory materials like mineral dust and soot (or biopolymers that tend to char upon heating), which are also not (or less efficiently) detected by AMS. During AMAZE-08, the $\kappa_{t}$ and $\kappa_{a}$ derived from 2- and 3-parameter fits to the measured $\mathrm{CCN}$ efficiency spectra were generally not much different (Table 1). Nevertheless, the differences observed for large particles $(\sim 5 \%$ at $D \approx 200 \mathrm{~nm}$ ) have a noticeable influence on the calculation of $\mathrm{CCN}$ number concentrations at low supersaturation as will be discussed below (Sect. 3.2).

The statistical uncertainty in the determination of activation diameters by curve fitting (standard error of the CDF fit parameters) was on average $\sim 2-3 \mathrm{~nm}(\sim 1-5 \%)$. According to the relative sensitivities specified by Kreidenweis et al. (2009), the uncertainty of $1-5 \%$ in diameter corresponds to an uncertainty of $3-15 \%$ in $\kappa$, and the uncertainty of $<10 \%$ in supersaturation reported above corresponds to an uncertainty of $<20 \%$ in $\kappa$.

\subsection{Determination of $\mathrm{CN}$ and $\mathrm{CCN}$ size distributions and number concentrations}

For each CCN measurement cycle, an average aerosol particle size distribution $\left(\mathrm{d} N_{\mathrm{CN}} / \mathrm{d} \log D\right)$ was determined from the size-resolved particle number concentrations measured with the CPC $\left(N_{\mathrm{CN}}\right)$. Multi-modal lognormal distribution functions were fitted to the measurement data (45 data points of $N_{\mathrm{CN}}$ vs. $D$ for $16-27$ discrete mobility diameter channels in the range of 20-290 $\mathrm{nm}$ selected with the DMA) using the algorithm DO-FIT of Hussein et al. (2005; version 4.20, limited to a maximum of 5 modes). The lognormal fit functions were used to map the measurement data onto a grid of 26 discrete mobility diameter channels with midpoints in the range of $D=21.6-819 \mathrm{~nm}$ and widths in the range of $\operatorname{dlog} D=0.053$ 0.079 that were found most suitable for robust data inversion according to Rissler et al. (2006). Upon data inversion, the counting efficiency for the CPC was assumed to be unity for 
Table 1. Characteristic CCN parameters (arithmetic mean values \pm standard deviations) averaged over the entire campaign (14 February12 March 2008), over the pristine focus period (6-12 March, 22:00 UTC), and over the rest of the campaign (14 February-6 March): midpoint activation diameters $\left(D_{a}, D_{t}\right)$, maximum activated fractions $\left(M A F_{f}, M A F_{m}\right)$, heterogeneity parameters $\left(\sigma_{a} / D_{a}, \sigma_{t} / D_{t}\right)$, hygroscopicity parameters $\left(\kappa_{a}, \kappa_{t}\right)$, number concentrations of aerosol particles with $D>30 \mathrm{~nm}\left(N_{\mathrm{CN}, 30}\right)$, number concentrations of cloud condensation nuclei $\left(N_{\mathrm{CCN}, \mathrm{S}}\right)$, integral CCN efficiencies $\left(N_{\mathrm{CCN}, \mathrm{S}} / N_{\mathrm{CN}, 30}\right)$, number of data points $(n)$. Subscripts a and $\mathrm{t}$ stand for parameters derived from 3-parameter and 2-parameter CDF fits to the measured CCN efficiency spectra, respectively. For corresponding median values see Table S1 (online supplement: http://www.atmos-chem-phys.net/9/7551/2009/acp-9-7551-2009-supplement.pdf). Concentration values are normalized to a reference state of $273 \mathrm{~K}$ and $1000 \mathrm{hPa}$.

\begin{tabular}{|c|c|c|c|c|c|c|c|c|c|c|c|c|c|c|}
\hline$S[\%]$ & $D_{a}[\mathrm{~nm}]$ & $D_{t}[\mathrm{~nm}]$ & $M A F_{f}$ & $M A F_{m}$ & $\sigma_{a}[\mathrm{~nm}]$ & $\sigma_{t}[\mathrm{~nm}]$ & $\sigma_{a} / D_{a}$ & $\sigma_{t} / D_{t}$ & $\kappa a$ & $\kappa_{t}$ & $N_{\mathrm{CN}, 30}\left[\mathrm{~cm}^{-3}\right]$ & $N_{\mathrm{CCN}, S}\left[\mathrm{~cm}^{-3}\right]$ & $N_{\mathrm{CCN}, S} / N_{\mathrm{CN}, 30}$ & $n$ \\
\hline \multicolumn{15}{|c|}{ Entire campaign } \\
\hline 0.10 & $199.0 \pm 18.3$ & $201.4 \pm 19.6$ & $0.91 \pm 0.12$ & $0.93 \pm 0.13$ & $11.2 \pm 8.8$ & $18.3 \pm 18.1$ & $0.06 \pm 0.05$ & $0.09 \pm 0.09$ & $0.202 \pm 0.06$ & $0.195 \pm 0.06$ & $261 \pm 235$ & $41 \pm 40$ & $0.16 \pm 0.12$ & 132 \\
\hline 0.19 & $127.9 \pm 12.4$ & $129.2 \pm 12.6$ & $0.99 \pm 0.08$ & $0.99 \pm 0.08$ & $10.9 \pm 7.7$ & $12.0 \pm 9.4$ & $0.09 \pm 0.07$ & $0.09 \pm 0.07$ & $0.202 \pm 0.06$ & $0.196 \pm 0.06$ & $243 \pm 199$ & $90 \pm 86$ & $0.36 \pm 0.13$ & 158 \\
\hline 0.28 & $105.3 \pm 10.9$ & $105.0 \pm 11.3$ & $1.00 \pm 0.12$ & $1.00 \pm 0.09$ & $9.1 \pm 7.1$ & $9.1 \pm 6.8$ & $0.09 \pm 0.07$ & $0.09 \pm 0.06$ & $0.166 \pm 0.05$ & $0.164 \pm 0.06$ & $243 \pm 189$ & $114 \pm 125$ & $0.43 \pm 0.13$ & 155 \\
\hline 0.46 & $82.8 \pm 8.8$ & $83.9 \pm 9.2$ & $1.00 \pm 0.08$ & $1.01 \pm 0.08$ & $8.3 \pm 5.9$ & $8.9 \pm 6.7$ & $0.10 \pm 0.07$ & $0.11 \pm 0.08$ & $0.122 \pm 0.04$ & $0.118 \pm 0.04$ & $246 \pm 188$ & $141 \pm 147$ & $0.53 \pm 0.13$ & 151 \\
\hline 0.82 & $54.6 \pm 3.8$ & $54.9 \pm 3.9$ & $1.00 \pm 0.06$ & $1.00 \pm 0.06$ & $4.0 \pm 2.7$ & $4.5 \pm 3.5$ & $0.07 \pm 0.05$ & $0.08 \pm 0.07$ & $0.127 \pm 0.03$ & $0.124 \pm 0.03$ & $237 \pm 198$ & $194 \pm 195$ & $0.74 \pm 0.11$ & 155 \\
\hline All & & & & & & & $0.081 \pm 0.066$ & $0.092 \pm 0.073$ & $0.162 \pm 0.061$ & $0.160 \pm 0.061$ & $256 \pm 223$ & & & 751 \\
\hline \multicolumn{15}{|c|}{ Focus period } \\
\hline 0.10 & $217.8 \pm 10.0$ & $222.4 \pm 12.0$ & $0.91 \pm 0.15$ & $0.92 \pm 0.16$ & $9.2 \pm 8.1$ & $16.3 \pm 17.3$ & $0.04 \pm 0.04$ & $0.07 \pm 0.07$ & $0.149 \pm 0.02$ & $0.141 \pm 0.02$ & $252 \pm 79$ & $18 \pm 11$ & $0.07 \pm 0.04$ & 38 \\
\hline 0.19 & $132.8 \pm 8.1$ & $133.7 \pm 7.6$ & $0.99 \pm 0.07$ & $0.99 \pm 0.07$ & $8.6 \pm 5.7$ & $9.4 \pm 7.3$ & $0.07 \pm 0.05$ & $0.07 \pm 0.05$ & $0.175 \pm 0.04$ & $0.171 \pm 0.03$ & $241 \pm 84$ & $76 \pm 32$ & $0.32 \pm 0.11$ & 44 \\
\hline 0.28 & $108.1 \pm 8.1$ & $108.0 \pm 8.8$ & $0.98 \pm 0.07$ & $0.98 \pm 0.07$ & $6.5 \pm 3.8$ & $6.7 \pm 3.8$ & $0.06 \pm 0.03$ & $0.06 \pm 0.04$ & $0.147 \pm 0.03$ & $0.148 \pm 0.04$ & $245 \pm 81$ & $98 \pm 34$ & $0.40 \pm 0.09$ & 41 \\
\hline 0.46 & $86.2 \pm 6.6$ & $86.6 \pm 6.2$ & $1.00 \pm 0.07$ & $1.00 \pm 0.07$ & $6.5 \pm 4.6$ & $6.5 \pm 4.0$ & $0.07 \pm 0.05$ & $0.07 \pm 0.03$ & $0.103 \pm 0.02$ & $0.105 \pm 0.02$ & $244 \pm 80$ & $128 \pm 44$ & $0.52 \pm 0.09$ & 42 \\
\hline 0.82 & $55.0 \pm 2.2$ & $56.0 \pm 2.4$ & $1.00 \pm 0.06$ & $1.01 \pm 0.06$ & $2.4 \pm 1.6$ & $2.7 \pm 3.1$ & $0.04 \pm 0.03$ & $0.05 \pm 0.06$ & $0.121 \pm 0.01$ & $0.115 \pm 0.02$ & $242 \pm 80$ & $194 \pm 70$ & $0.78 \pm 0.05$ & 43 \\
\hline All & & & & & & & $0.06 \pm 0.04$ & $0.06 \pm 0.05$ & $0.138 \pm 0.04$ & $0.137 \pm 0.04$ & $243 \pm 88$ & & & 208 \\
\hline \multicolumn{15}{|c|}{ Rest of campaign } \\
\hline 0.10 & $191.4 \pm 15.0$ & $193.3 \pm 15.9$ & $0.91 \pm 0.11$ & $0.93 \pm 0.11$ & $12.0 \pm 8.9$ & $19.0 \pm 18.5$ & $0.06 \pm 0.05$ & $0.10 \pm 0.09$ & $0.224 \pm 0.06$ & $0.216 \pm 0.06$ & $280 \pm 287$ & $50 \pm 42$ & $0.20 \pm 0.12$ & 94 \\
\hline 0.19 & $126.0 \pm 13.3$ & $127.5 \pm 13.8$ & $0.98 \pm 0.08$ & $0.99 \pm 0.09$ & $11.8 \pm 8.9$ & $13.1 \pm 10.0$ & $0.10 \pm 0.07$ & $0.10 \pm 0.08$ & $0.213 \pm 0.07$ & $0.206 \pm 0.07$ & $260 \pm 243$ & $97 \pm 99$ & $0.37 \pm 0.14$ & 114 \\
\hline 0.28 & $104.2 \pm 11.6$ & $103.9 \pm 11.9$ & $1.00 \pm 0.14$ & $1.01 \pm 0.10$ & $10.0 \pm 7.8$ & $10.0 \pm 7.4$ & $0.10 \pm 0.07$ & $0.10 \pm 0.07$ & $0.172 \pm 0.06$ & $0.170 \pm 0.06$ & $254 \pm 228$ & $121 \pm 145$ & $0.44 \pm 0.14$ & 114 \\
\hline 0.46 & $81.5 \pm 9.2$ & $82.8 \pm 10.0$ & $1.00 \pm 0.08$ & $1.01 \pm 0.08$ & $9.0 \pm 6.3$ & $9.8 \pm 7.3$ & $0.11 \pm 0.07$ & $0.12 \pm 0.08$ & $0.128 \pm 0.04$ & $0.125 \pm 0.05$ & $262 \pm 229$ & $146 \pm 172$ & $0.53 \pm 0.15$ & 109 \\
\hline 0.82 & $54.4 \pm 4.2$ & $55.5 \pm 4.3$ & $0.99 \pm 0.06$ & $1.00 \pm 0.07$ & $4.7 \pm 2.8$ & $5.3 \pm 3.4$ & $0.09 \pm 0.05$ & $0.10 \pm 0.06$ & $0.129 \pm 0.03$ & $0.128 \pm 0.03$ & $250 \pm 242$ & $194 \pm 227$ & $0.73 \pm 0.13$ & 112 \\
\hline All & & & & & & & $0.09 \pm 0.07$ & $0.10 \pm 0.08$ & $0.171 \pm 0.07$ & $0.169 \pm 0.07$ & $256 \pm 257$ & & & 543 \\
\hline
\end{tabular}

all particles, and losses in the sampling lines were neglected. Note that the size distributions displayed in this manuscript extend beyond the upper limit of the measurement range and have to be regarded as extrapolations for $D>290 \mathrm{~nm}$. Due to the low concentration of larger particles, however, this has relatively little influence on the reported $\mathrm{CN}$ and $\mathrm{CCN}$ concentrations and integral $\mathrm{CCN}$ efficiencies, respectively.

Aerosol particle $(\mathrm{CN})$ number concentrations were calculated by linear interpolation and stepwise integration of the $\mathrm{CN}$ size distributions with a resolution of $\operatorname{d} \log D=0.0083$ (Rose et al., 2008b). Integral number concentrations have been calculated for the whole measurement size range starting at $20 \mathrm{~nm}\left(N_{\mathrm{CN}, 20}\right)$, and for aerosol particles with $D>30 \mathrm{~nm}\left(N_{\mathrm{CN}, 30}\right)$. The $N_{\mathrm{CN}, 30}$ values were used for further analysis and discussion, because they are less influenced by nucleation mode particles $(\sim 20 \mathrm{~nm})$, which are highly variable in concentration, difficult to measure with high precision (diffusion losses), and generally not CCN-active at $S<1 \%$. Note that $30 \mathrm{~nm}$ is the critical diameter for $\mathrm{CCN}$ activation of pure ammonium sulfate particles at $S \approx 1 \%$ (Rose et al., 2008a).

The number size distributions obtained by inversion of the CPC measurement data from the DMA-CPC-CCNC system (DMPS) were compared to the results obtained with an SMPS system operated in parallel by Lund University (Roldin et al., 2008), for the period during which both systems were fully operational ( $\sim 40 \%$ of the CCN measurement period), and the results were found to be in fair agreement. The SMPS median values were $\sim 20 \%$ lower for $N_{\mathrm{CN}, 20}$, $\sim 5 \%$ lower for $N_{\mathrm{CN}, 30}$, and $\sim 5 \%$ lower for the geomet- ric mean diameters of the Aitken and accumulation modes. These differences are likely due to larger diffusion losses or lower counting efficiencies of the SMPS for small particles.

Averaged over the CCN measurement period, the DMPS values of $N_{\mathrm{CN}, 20}$ as reported in this paper were $\sim 25 \%$ lower than the aerosol particle number concentrations determined with a separate CPC (TSI 3010). To some extent this can be explained by the lower cut-off diameter $(\sim 10 \mathrm{~nm}$ vs. $\sim 20 \mathrm{~nm}$ ) and higher time-resolution (1 s vs. $3 \mathrm{~h}$ ) of the CPC standalone measurements, which are thus more sensitive to nucleation mode particles and short-term events of elevated aerosol concentration. Some deviations may also be due to the DMPS data inversion, diffusive and evaporative losses of small particles in the DMA (lower RH), and potential differences in the CPC flow rates and counting efficiencies. The CPC of the CCN measurement setup (TSI 3762) was calibrated by the manufacturer directly before the campaign, and the deviations from a reference counter were $\leq 3 \%$.

$\mathrm{CCN}$ size distributions $\left(\mathrm{d} N_{\mathrm{CCN}} / \mathrm{d} \log D\right)$ were calculated by multiplying the CCN efficiency spectra (3-parameter CDF fits of $\left.N_{\mathrm{CCN}} / N_{\mathrm{CN}}\right)$ with the total aerosol particle number size distributions derived from the $\mathrm{CPC}$ measurement data $\left(\mathrm{d} N_{\mathrm{CN}} / \mathrm{d} \log D\right)$, and $\mathrm{CCN}$ number concentrations $(N C C N, S)$ were calculated by stepwise integration of the CCN size distributions (for further details see Rose et al. (2008b). 


\subsection{Aerosol mass spectrometry (AMS)}

An Aerodyne high-resolution time-of-flight aerosol mass spectrometer (HR-ToF-AMS, referred as "AMS" for brevity) was used to measure size-resolved chemical composition of non-refractory submicron aerosol particles (DeCarlo et al., 2006; Canagaratna et al., 2007; Chen et al., 2009). The AMS data used in this study comprise a time series of integral mass concentrations ( $\sim 5 \mathrm{~min}$ time resolution) and a time series of mass size distributions $\left(\mathrm{d} M / \mathrm{d} \log d_{\mathrm{va}}, \operatorname{dlog} d_{\mathrm{va}}=0.05\right.$, $\sim 6 \mathrm{~h}$ time resolution limited by signal-to-noise) where $d_{\mathrm{va}}$ is the vacuum aerodynamic diameter (DeCarlo et al., 2004).

The AMS uses an aerodynamic lens system to focus the particles in a narrow beam and deliver the particles to the high-vacuum detection region. This system is capable of focusing particles with $d_{\mathrm{va}} \approx 30-1000 \mathrm{~nm}$ with size-dependent particle transmission efficiency ( $E_{L}$; Liu et al., 2007). In this study, we operated the AMS at sampling pressures of $867-907 \mathrm{hPa}$. Under these conditions, $E_{L}$ is close to $100 \%$ for particles with $d_{\mathrm{va}} \approx 100-400 \mathrm{~nm}$ and is greater than $20 \%$ for particles with $d_{\mathrm{va}} \approx 50-1000 \mathrm{~nm}$. For organic measurements, the estimated uncertainty is about $30 \%$ at loadings of $\sim 1 \mu \mathrm{g} \mathrm{m}^{-3}$ to $40 \%$ at loadings of $\sim 0.5 \mu \mathrm{g} \mathrm{m}^{-3}$, and it can increase to $100 \%$ for low organic loadings $\left(\sim 0.1 \mu \mathrm{g} \mathrm{m}^{-3}\right)$. For sulfate measurements, the uncertainty is $<10 \%$ for high loadings $\left(\sim 0.5 \mu \mathrm{g} \mathrm{m}^{-3}\right)$ and about $40 \%$ for low loadings ( 0.05 $\left.\mu \mathrm{g} \mathrm{m}^{-3}\right)$. Organic and inorganic mass fractions were calculated from the AMS mass concentrations as detailed in Sect. 3.3 (Eq. 3).

To make the size-resolved AMS data directly comparable with the size-resolved CCN data, the AMS $d_{\mathrm{va}}$ values were divided by a density scaling factor of 1.4 to obtain approximate mobility equivalent diameters $(D)$ as used throughout this manuscript. The scaling factor is based on the campaignaverage effective particle density of $1.4 \mathrm{~g} \mathrm{~cm}^{-3}$ determined by Chen et al. (2009) from AMS and SMPS measurements according to DeCarlo et al. (2004); it is in good agreement with earlier laboratory and field measurements of organicrich aerosol particles (Cross et al., 2007; Kostenidou et al., 2007).

For scatter plots and correlations, the non-size-resolved AMS data were averaged over the time intervals of the $\mathrm{CCN}$ measurements $(\sim 35 \mathrm{~min}$ per $\mathrm{CCN}$ efficiency spectrum; $1-$ 6 AMS data points per $\mathrm{CCN}$ data point). With regard to the size resolved AMS data, the CCN measurement data were averaged over the AMS averaging intervals $(\sim 6 \mathrm{~h}$ per AMS size distribution; $1-5 \mathrm{CCN}$ data points per AMS data point), and the AMS size distributions were integrated around the midpoint diameters of the CCN efficiency spectra $\left(D_{a} \pm \sigma_{a}\right)$.

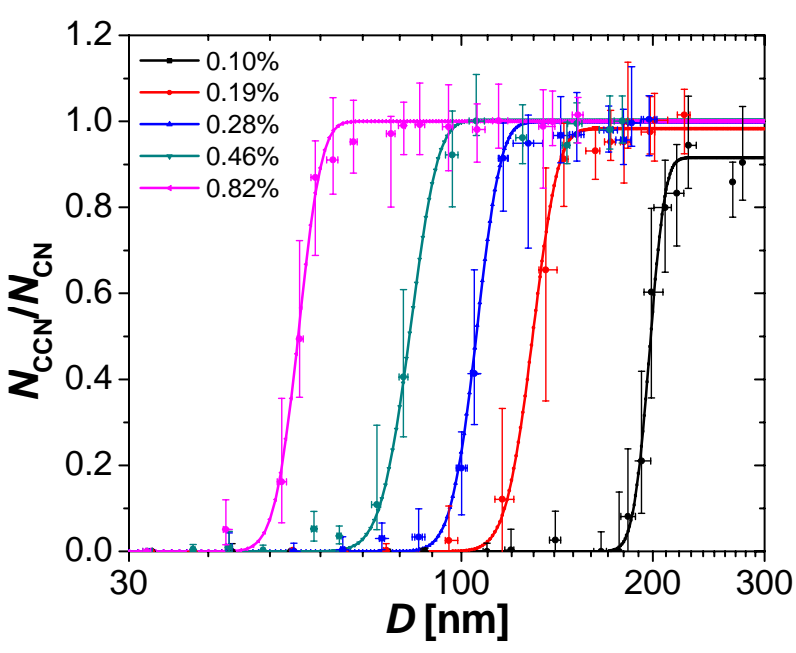

Fig. 2. Size-resolved CCN efficiency spectra at different levels of supersaturation $(S=0.10-0.82 \%)$ averaged over the entire campaign: activated particle fraction $N_{\mathrm{CCN}} / N_{\mathrm{CN}}$ plotted against mobility equivalent diameter $D$. The data points are median values, the error bars extend from the lower to the upper quartiles, and the lines are 3-parameter cumulative Gaussian distribution function (CDF) fits.

\section{Results and discussion}

\subsection{CCN efficiency spectra and related parameters}

\subsubsection{Campaign averages}

From the 30 day campaign period of AMAZE-2008, we have obtained 751 size-resolved CCN efficiency spectra (activation curves) for atmospheric aerosols at five water vapor supersaturations in the range of $S=0.10-0.82 \%$. Figure 2 shows campaign averages of the atmospheric $\mathrm{CCN}$ efficiency spectra at the different supersaturation levels. The average parameters derived from the $\mathrm{CCN}$ efficiency spectra are summarized in Table 1 (arithmetic mean value \pm standard deviation), and the corresponding median values and statistical distributions are given in the online supplementary material (Table S1, Figs. S1-S2: http://www.atmos-chem-phys.net/9/ 7551/2009/acp-9-7551-2009-supplement.pdf). Note that in this paper the terms "entire campaign", "campaign average" and similar expressions generally refer to the period during which the presented size-resolved $\mathrm{CCN}$ measurements were performed (14 February-12 March 2008, excluding 2-5 March and some short-term interruptions) but not to the full duration of the AMAZE-08 campaign (7 February14 March 2008).

As expected, the midpoint activation diameters $D_{a}$ increased with decreasing $S$ and were larger than the critical diameters for $\mathrm{CCN}$ activation of pure ammonium sulfate particles at the given supersaturation levels. In general, the 


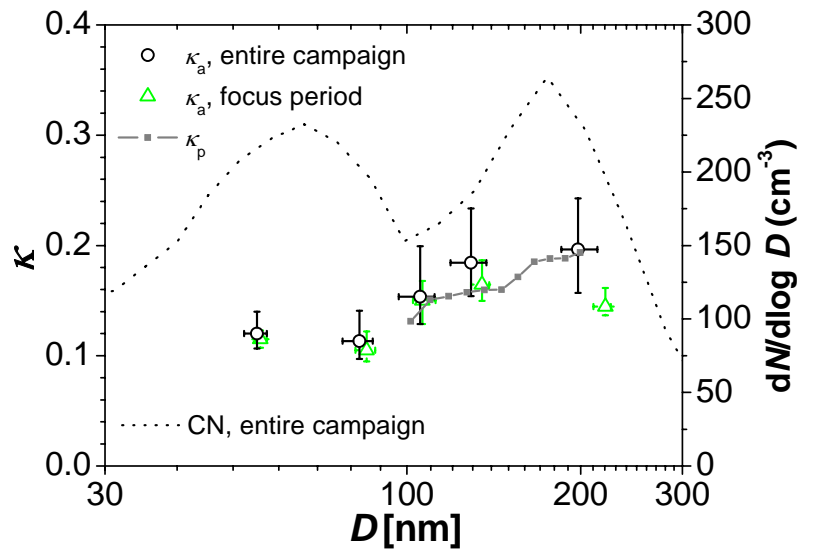

Fig. 3. Effective hygroscopicity parameters plotted against midpoint activation diameters derived from $\mathrm{CCN}$ efficiency spectra $(\kappa$ and $D_{a}$ from 3-parameter CDF fits) averaged over the entire campaign (black circles) and over the focus period (green triangles, 6$12 \mathrm{March})$, respectively. The data points are median values corresponding to a given level of supersaturation $(S=0.10-0.82 \%)$, and the error bars extend to from the lower to the upper quartiles. Gray squares and line indicate the effective hygroscopicity parameters predicted from campaign median organic and inorganic mass fractions determined by size-resolved AMS measurements $\left(\kappa_{p}\right)$. Dotted line shows the median number size distribution of total aerosol particles $(\mathrm{CN})$ averaged over the entire campaign.

$\mathrm{CCN}$ efficiency spectra reached up to one $\left(M A F_{f} \approx 1\right)$ and the normalized standard deviations of the 3-parameter CDF fits were small $\left(\sigma_{a} / D_{a} \approx 10 \%\right)$, which implies that nearly all aerosol particles larger than the midpoint activation diameter $\left(D>D_{a}\right)$ were $\mathrm{CCN}$-active.

At the lowest supersaturation level $(S=0.10 \%)$, however, the maximum activated fraction remained on average below one, which indicates the presence of a small fraction of externally mixed $\mathrm{CCN}$-inactive particles with much lower hygroscopicity at $D \approx 200-250 \mathrm{~nm}$. The average $M A F_{f}$ was only $\sim 0.9$ with minimum values around $\sim 0.7$, implying that on average $\sim 10 \%$ and up to $\sim 30 \%$ of the aerosol particles $>200 \mathrm{~nm}$ were not $\mathrm{CCN}$-active at $S=0.10 \%$. According to the $\kappa$-Köhler model, particles as large as $\sim 250 \mathrm{~nm}$ must have an effective hygroscopicity parameter $\kappa<0.1$ to be not activated at that supersaturation level (Petters and Kreidenweis, 2007; Rose, et al., 2008b), indicating substantial proportions of water-insoluble components (e.g. biological materials, black carbon or mineral dust; Petters and Kreidenweis, 2007; Kreidenweis et al., 2009; Pöschl et al., 2009a, b; Sinha et al., 2009).

Figure 3 gives an overview of the effective hygroscopicity parameters $\left(\kappa_{a}\right)$ that have been derived from the midpoint activation diameters $\left(D_{a}\right)$ of the 3-parameter $\mathrm{CDF}$ fits to the measured CCN efficiency spectra (Sect. 2.2). For particles in the Aitken size range $(\sim 50-80 \mathrm{~nm})$, the $\kappa$ values were close to $\sim 0.1$, which is characteristic for secondary organic aerosol components (King et al., 2007; Petters and Kreidenweis, 2007; Andreae and Rosenfeld, 2008; Dusek et al., 2009a, b; Engelhart et al., 2008; Asa-Awuku et al., 2009; King et al., 2009). In the accumulation size range ( $\sim 100-200 \mathrm{~nm}), \kappa$ increased to $\sim 0.2$ when averaged over the entire campaign, or to $\sim 0.15$ when averaged over a pristine focus period at the end of the campaign, as will be discussed below (Sect. 3.1.2).

Averaged over the full range of aerosol particle sizes and water vapor supersaturations, the median value of the effective hygroscopicity parameter for the Amazonian aerosols investigated during the AMAZE-08 campaign was $\kappa \approx 0.15$ (Table S1: http://www.atmos-chem-phys.net/9/7551/2009/ acp-9-7551-2009-supplement.pdf). This value is consistent with earlier studies of aerosol particle hygroscopicity during the wet season in Amazonia (Sect. 3.1.3), but it is by a factor of two lower than the values typically reported for continental aerosols in other regions of the world (Andreae and Rosenfeld, 2008; Rose et al., 2008b; Kreidenweis et al., 2009; Pöschl et al., 2009a; and references therein).

\subsubsection{Time series and focus period}

Figure 4 shows the time series of characteristic parameters derived from the 3-parameter fits to the $\mathrm{CCN}$ efficiency spectra measured throughout the campaign $\left(D_{a}, \kappa_{a}\right.$, $\sigma_{a},\left(D_{a}, M A F_{f}\right)$. For clarity, the parameters in Fig. $4 \mathrm{~b}-$ $\mathrm{d}$ are shown only for the lowest and highest investigated supersaturation levels. The values and temporal evolution of the parameters determined at intermediate supersaturation levels were generally in between those observed at $S=0.10 \%$ and $0.82 \%$. As for the campaign average values (Table 1), also the time series of the 2-parameter fit results were not much different from the 3-parameter fit results (for time series of $D_{t}, \kappa_{t}$ and $\sigma_{t} / D_{t}$ see online supplement, Fig. S3: http://www.atmos-chem-phys.net/9/7551/ 2009/acp-9-7551-2009-supplement.pdf).

Most parameters exhibited some short-time variability and spikes that can be attributed to local emissions, long-range transport, and precipitation events, respectively (Chen et al., 2008, 2009; Martin et al., 2009a, b). In addition to shorttime fluctuations, the hygroscopicity parameters observed at $S=0.10 \%$, i.e. for accumulation mode particles with diameters around $\sim 200 \mathrm{~nm}$, exhibited a pronounced increase from $\sim 0.15$ on 18 February to $\sim 0.3$ on 1 March. After a power outage and subsequent repair work on 2-6 March, the $\kappa$ values were again around $\sim 0.15$.

Based on the AMS data, the variations in $\kappa$ observed at $S=0.1 \%$ can be explained by variations in the organic mass fraction of the accumulation mode particles (Sect. 3.3). The factors regulating the variations in aerosol composition and organic mass fraction are not yet fully understood but likely to include local and regional emission and formation of particles (mostly secondary organic aerosol) as well as long-range transport of sea salt, mineral dust or biomass burning particles (Chen et al., 2008, 2009; Martin et al., 

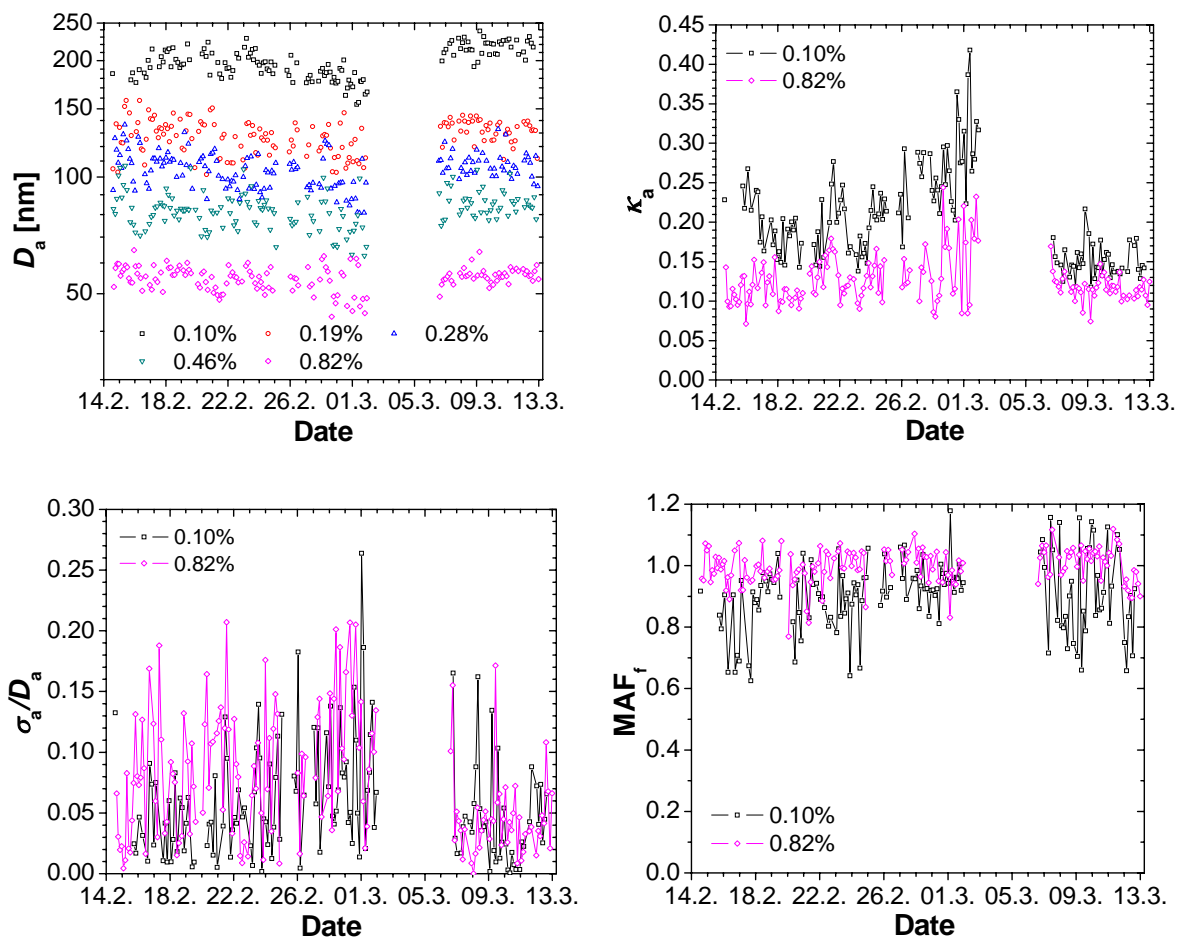

Fig. 4. Time series of characteristic parameters derived from the CCN efficiency spectra (3-parameter CDF fits) observed at different levels of supersaturation $(S=0.10-0.82 \%)$ plotted against the date in February-March 2008 (UTC): midpoint activation diameter $\left(D_{a}\right)$, effective hygroscopicity parameter $(\kappa)$, heterogeneity parameter $\left(\sigma / D_{a}\right)$, and maximum activated fraction $\left(M A F_{f}\right)$.

2009a, b; Pöschl et al., 2009b; Sinha et al., 2009). To specifically characterize the CCN properties of aerosol particles in pristine rainforest air, we have chosen a focus period of 6-12 March (start/end 22:00 UTC corresponding to 18:00 local time). This was the longest continuous period during AMAZE-08 with very low aerosol concentrations and high organic mass fractions, which is indicative of minimal influence by long-range transport or local pollution and may thus be most representative of the inherent properties of the Amazonian ecosystem (Chen et al., 2008, 2009; Martin et al., 2009b). The average CCN parameters for the focus period and for the rest of the campaign are summarized in Table 1, and statistical distributions are shown in the online supplement (Figs. S4-S5: http://www.atmos-chem-phys.net/9/ 7551/2009/acp-9-7551-2009-supplement.pdf).

As illustrated in Fig. 3 and detailed in Table 1, the effective hygroscopicity of accumulation mode particles was substantially lower during the focus period than during the rest of the campaign $(\sim 30 \%$ at $D \approx 200 \mathrm{~nm})$, whereas little difference was observed for Aitken mode particles ( $D \approx 50-90 \mathrm{~nm})$. At $S=0.10 \%$ not only $\kappa$ but also $M A F$ was lower during the focus period (Table 1), indicating a higher proportion of externally mixed CCN-inactive particles at $D \geq 200 \mathrm{~nm}$. These and other aspects of aerosol composition and mixing state will be discussed below (Sects. 3.3 and 4) and in follow-up studies (Pöschl et al., 2009b; Sinha et al., 2009).
During the interactive public discussion of this manuscript, Roberts (2009) pointed out that the $\kappa$ values observed at $S=0.1 \%(D \approx 200 \mathrm{~nm})$ during the pristine focus period were by a factor of $\sim 4$ lower than the $\kappa$ values observed at remote maritime locations for accumulation mode particles of comparable size $(\kappa \approx 0.6$, equivalent to pure ammonium sulfate; Roberts et al., 2008). In view of the enhanced sensitivity of cloud droplet formation to aerosol hygroscopicity at low supersaturation (updraft limited regime of CCN activation; Reutter et al., 2009), this may be a potentially important difference between "blue ocean" and "green ocean" regimes (Andreae et al., 2004; Roberts, 2009).

\subsubsection{Comparison with other studies}

Earlier studies investigating the hygroscopicity and $\mathrm{CCN}$ activity of aerosol particles in Amazonia during the wet season did not use the effective hygroscopicity parameter $\kappa$ but various other parameters to characterize the hygroscopicity of aerosol particles (Zhou et al., 2002; Rissler et al., 2006; Vestin et al., 2007; Roberts et al., 2001, 2002): soluble volume fractions referring to an equivalent of ammonium sulfate, $\varepsilon_{\mathrm{AS}}$, or ammonium hydrogen sulfate (bisulfate), $\varepsilon_{\mathrm{AHS}}$, or equivalent molar densities of soluble molecules or ions, $\rho_{\text {ion }}\left(\mathrm{mol} \mathrm{m}^{-3}\right)$, respectively. For efficient comparison, we 
have converted these parameters into effective hygroscopicity parameters using the following equation (Petters and Kreidenweis, 2007; Rose et al., 2008a):

$\kappa \approx \kappa_{\mathrm{AS}} \times \varepsilon_{\mathrm{AS}} \approx \kappa_{\mathrm{AHS}} \times \varepsilon_{\mathrm{AHS}} \approx \rho_{\mathrm{ion}} /\left(\rho_{w} / M_{w}\right)$

$\kappa_{\mathrm{AS}}$ and $\kappa_{\mathrm{AHS}}$ are the effective hygroscopicity parameters of ammonium sulfate and ammonium hydrogen sulfate, respectively $\left(\kappa_{\mathrm{AS}} \approx \kappa_{\mathrm{AHS}} \approx 0.6\right) ;\left(\rho_{w} / M_{w}\right) \approx 55^{\times} 10^{3} \mathrm{~mol} \mathrm{~m}^{-3}$ is the molar density of liquid water (ratio of water density and molar mass). Note that Rissler et al. (2006) and Vestin et al. (2007) had introduced the symbol $\kappa$ instead of the symbol $\rho_{\text {ion }}$, which was introduced by Wex et al. (2007). In view of the widespread use of the symbol $\kappa$ for the effective hygroscopicity coefficient as introduced by Petters and Kreidenweis (2007), we took the symbol $\rho_{\text {ion }}$ for the equivalent molar density of soluble ions or molecules in the dry particle. The term and subscript "ion" appears not ideally suited for the description of water-soluble organic compounds, but we did not want to introduce yet another different symbol at this point.

The exact values of $\kappa, \kappa_{\mathrm{AS}}, \kappa_{\mathrm{AHS}}, \varepsilon_{\mathrm{AS}}, \varepsilon_{\mathrm{AHS}}$ and $\rho_{\text {ion }}$ depend on the underlying Köhler model assumptions about the Kelvin and Raoult terms describing the influence of the particle material on the surface tension and water activity of the aqueous droplet formed upon $\mathrm{CCN}$ activation (composition and concentration dependence of surface tension, osmotic coefficients, van't Hoff factors, etc.; Rose et al., 2008a). Earlier studies have not always unambiguously specified the exact input parameters and formalisms used to determine the reported equivalent soluble volume fractions. In view of other uncertainties related to the experimental calibration and model calculation of water vapor supersaturations, however, the approximation $\kappa \approx 0.6 \cdot \varepsilon_{\mathrm{AS}} \approx 0.6 \cdot \varepsilon_{\mathrm{AHS}} \approx \rho_{\mathrm{ion}} /\left(55 \times 10^{3} \mathrm{~mol} \mathrm{~m}^{-3}\right)$ should be suitable for comparing HTDMA and CCNC field measurement data from different studies (Anderson et al., 2009; Kreidenweis et al., 2008, 2009; Rose et al., 2008a; Pöschl et al., 2009a).

The studies of Rissler et al. (2006) and Vestin (2007) are based on the same HTDMA measurement data sets from the LBA-SMOCC campaign. Compared to AMAZE08 (average particle number concentration $\sim 200 \mathrm{~cm}^{-3}$ ), the "wet period" of LBA-SMOCC at the beginning of the wet season (31 October-14 November 2002) appeared to be more strongly influenced by pyrogenic aerosols from local and regional sources (average particle number concentration $\sim 800 \mathrm{~cm}^{-3}$ ). As discussed by Rissler et al. (2006) and Vestin et al. (2007), the data from LBA-SMOCC exhibited pronounced diel cycles, where the daytime values were less polluted. Because the afternoon hours are most relevant for the influence of aerosols on the development of convective clouds we focus our comparison on the data reported by Vestin et al. (2007) for this time of day (12:00-16:00 local time). Note that the campaign average $\mathrm{CCN}$ and $\mathrm{CN}$ measurement data of AMAZE-08 exhibited no pronounced diel cycles (Fig. S6 in the online supplement: http://www.atmos-chem-phys.net/9/7551/ 2009/acp-9-7551-2009-supplement.pdf), which is consistent with the trends reported from LBA-SMOCC (i.e. less pronounced diel cycles at lower pollution levels) and confirms that the influence of local or regional pollution was very low during AMAZE-08.

Table 2 gives an overview of parameters characterizing the externally mixed groups of atmospheric aerosol particles with different hygroscopic properties as observed in the HTDMA measurements of Zhou et al. (2002) and Vestin et al. (2007) during the wet season in Amazonia. These and other HTDMA field measurement studies have used various different designations for the externally mixed groups of particles, including the attributes "hydrophobic" or "nearly hydrophobic", which appear not very well suited to characterize particles that are able to absorb water vapor (albeit not very efficiently). For consistency, we propose and use the following designations: particles with very low hygroscopicity (VLH, $\kappa<0.1$ ), low hygroscopicity (LH, $\kappa \approx 0.1-0.2$ ), medium hygroscopicity (MH, $\kappa \approx 0.2-0.4$ ), or high hygroscopicity (HH, $\kappa>0.4$; not relevant in this study).

Zhou et al. (2002) and Vestin et al. (2007) reported also CCN concentrations determined with a CCNC, but the CCNC data were not used to derive effective hygroscopicity parameters for the ensemble of aerosol particles that are $\mathrm{CCN}$-active at a given supersaturation $\left(\kappa_{a}\right)$, or for the overall population of $\mathrm{CCN}$-active and $\mathrm{CCN}$-inactive particles $\left(\kappa_{t}\right)$. To obtain a proxy for the effective hygroscopicity of the overall population of aerosol particles, we have averaged the $\kappa$ values of the different groups of particles observed in the HTDMA experiments (VLH, LH, MH; weighted by their number fraction and relative frequency of occurrence), and we have designated this parameter as $\kappa_{t, \text { avg. }}$.

As illustrated in Fig. 5, the $\kappa_{t}$,avg values derived from the results of Vestin et al. (2007) are very similar to the campaign average $\kappa_{t}$ values determined in the present study. They range from $\sim 0.12$ for Aitken mode particles to $\sim 0.20$ for accumulation mode particles with an overall mean value of $\sim 0.15$ (Table 2). The $\kappa_{t}$,avg values derived from Zhou et al. (2002) are somewhat lower and similar to the $\kappa_{t}$ values determined in the focus period of the present study, ranging from $0.10-0.12$ in the Aitken size range to 0.17 in the accumulation size range (overall mean value $\sim 0.13$, Table 2 ).

At the bottom of Table 2 we have summarized the CCNC measurement results of the present study in a format analogous to the presentation of the HTDMA measurement results of earlier studies. The size resolved CCNC measurements do not enable the distinction of externally mixed groups of aerosol particles with different hygroscopicity (VLH, LH, $\mathrm{MH}$ ), but they do enable the detection of externally mixed groups of particles that are $\mathrm{CCN}$-active or $\mathrm{CCN}$-inactive at a given supersaturation and size $(M A F<1)$.

Assuming that the $\mathrm{CCN}$-inactive particles observed at $S=0.10 \%$ and $D \geq 200 \mathrm{~nm}$ had the same effective 
Table 2. Parameters characterizing the size-resolved hygroscopicity of aerosol particles in Amazonia during the wet season as observed in earlier studies (HTDMA measurements, campaign average values) and in the present study (CCNC measurements, campaign average and pristine focus period): soluble volume fractions referring to an equivalent of ammonium sulfate $\left(\varepsilon_{\mathrm{AS}}\right)$ or ammonium hydrogen sulfate $\left(\varepsilon_{\mathrm{AHS}}\right)$; equivalent molar densities of soluble molecules or ions $\left(\rho_{\text {ion }}\right)$; effective hygroscopicity parameters for specific groups and/or size ranges of aerosol particles $\left(\kappa, \kappa_{a}\right)$; effective hygroscopicity parameters characterizing the overall aerosol particle population as obtained by averaging over different externally mixed particle groups $\kappa_{t}$, avg $=\Sigma_{j}\left(\kappa_{j} \times f_{n, j} \times f_{o, j}\right)$ or by fitting of measured CCN efficiency spectra $\left(\kappa_{t}, 2\right.$-parameter CDF fit); number fraction $\left(f_{n}\right)$ and relative frequency of occurrence $\left(f_{o}\right)$ of specific particle groups. The externally mixed particle groups that were detected and differently named in different HTDMA studies are consistently classified according to their hygroscopicity: very low hygroscopicity (VLH, $\kappa<0.1$ ), low hygroscopicity $(\mathrm{LH}, \kappa \approx 0.1-0.2$ ), and medium hygroscopicity $(\mathrm{MH}, \kappa \approx 0.2-0.4)$.

\begin{tabular}{|c|c|c|c|c|c|c|c|c|c|c|c|}
\hline Particle Group & Parameters & & & & & & & Aitken Mode & Accumulation Mode & $\begin{array}{l}\text { Aitken and } \\
\text { Accumulation Mode }\end{array}$ & Comments, References \\
\hline \multirow{3}{*}{ VLH } & $D(\mathrm{~nm})$ & 35 & 50 & 75 & 110 & 165 & 265 & $30-100$ & $100-300$ & $30-300$ & \multirow{8}{*}{$\begin{array}{l}\text { HTDMA, Sep-Nov } \\
\text { 2002, LBA-SMOCC, } \\
\text { Rondônia, Brazil; } \\
\text { VLH="nearly } \\
\text { hydrophobic particles", } \\
\text { LH="moderately } \\
\text { hygroscopic particles"; } \\
\text { Vestin et al., } 2007\end{array}$} \\
\hline & $\rho_{\text {ion }}\left(\mathrm{mol} \mathrm{m}^{-3}\right)$ & 4369 & 4580 & 4518 & 4160 & 3954 & 4270 & 4489 & 4128 & 4308.5 & \\
\hline & $\kappa$ & 0.079 & 0.083 & 0.082 & 0.075 & 0.071 & 0.077 & 0.081 & 0.075 & 0.078 & \\
\hline \multirow{4}{*}{ LH } & $f_{n}$ & 0.41 & 0.48 & 0.56 & 0.33 & 0.19 & 0.2 & 0.483 & 0.24 & 0.362 & \\
\hline & $\rho_{\text {ion }}\left(\mathrm{mol} \mathrm{m}^{-3}\right)$ & 8396 & 8378 & 9401 & 11039 & 10853 & 12463 & 8725 & 11452 & 10088 & \\
\hline & $\kappa$ & 0.152 & 0.151 & 0.170 & 0.199 & 0.196 & 0.225 & 0.158 & 0.207 & 0.182 & \\
\hline & $f_{n}$ & 0.59 & 0.52 & 0.44 & 0.67 & 0.81 & 0.8 & 0.517 & 0.76 & 0.638 & \\
\hline \multirow[t]{2}{*}{ All } & $\kappa_{t, \text { avg }}$ & 0.122 & 0.118 & 0.120 & 0.158 & 0.172 & 0.196 & 0.120 & 0.175 & 0.148 & \\
\hline & $D(\mathrm{~nm})$ & 35 & 50 & 73 & 109 & 166 & 264 & $30-100$ & $100-300$ & $30-300$ & \multirow{14}{*}{$\begin{array}{l}\text { HTDMA, Mar-Apr } \\
\text { 1998, CLAIRE-98, } \\
\text { Balbina, Brazil; } \\
\text { VLH="hydrophobic } \\
\text { particles", LH="less } \\
\text { hygroscopic particles", } \\
\text { MH="more } \\
\text { hygroscopic particles"; } \\
\text { Zhou et al., } 2002\end{array}$} \\
\hline \multirow[t]{4}{*}{ VLH } & $\varepsilon_{\mathrm{AHS}}$ & 0.05 & 0.04 & 0.03 & 0.02 & 0.01 & 0.02 & 0.04 & 0.017 & 0.028 & \\
\hline & $\kappa$ & 0.03 & 0.024 & 0.018 & 0.012 & 0.006 & 0.012 & 0.024 & 0.01 & 0.017 & \\
\hline & $f_{n}$ & 0.32 & 0.38 & 0.45 & 0.46 & 0.31 & 0.24 & 0.383 & 0.337 & 0.360 & \\
\hline & $f_{o}$ & 0.06 & 0.05 & 0.09 & 0.13 & 0.14 & 0.11 & 0.067 & 0.127 & 0.097 & \\
\hline \multirow[t]{4}{*}{ LH } & $\varepsilon_{\mathrm{AS}}$ & 0.17 & 0.15 & 0.14 & 0.18 & 0.21 & 0.27 & 0.153 & 0.22 & 0.187 & \\
\hline & $\kappa$ & 0.102 & 0.09 & 0.084 & 0.108 & 0.126 & 0.162 & 0.092 & 0.132 & 0.112 & \\
\hline & $f_{n}$ & 0.96 & 0.97 & 0.96 & 0.93 & 0.94 & 0.97 & 0.963 & 0.947 & 0.955 & \\
\hline & $f_{o}$ & 1 & 0.95 & 0.94 & 0.96 & 0.95 & 0.97 & 0.963 & 0.960 & 0.962 & \\
\hline \multirow[t]{4}{*}{$\varepsilon_{\mathrm{AHS}}$} & 0.6 & 0.41 & 0.37 & 0.4 & 0.42 & 0.52 & 0.46 & 0.447 & 0.453 & & \\
\hline & $\kappa$ & 0.36 & 0.246 & 0.222 & 0.24 & 0.252 & 0.312 & 0.276 & 0.268 & 0.272 & \\
\hline & $f_{n}$ & 0.37 & 0.68 & 0.85 & 0.83 & 0.82 & 0.96 & 0.633 & 0.870 & 0.752 & \\
\hline & $f_{o}$ & 0.07 & 0.09 & 0.06 & 0.06 & 0.07 & 0.03 & 0.073 & 0.053 & 0.063 & \\
\hline \multirow[t]{3}{*}{ All } & $\kappa_{t, \text { avg }}$ & 0.108 & 0.098 & 0.088 & 0.109 & 0.127 & 0.162 & 0.098 & 0.133 & 0.115 & \\
\hline & $D_{a}(\mathrm{~nm})$ & & 54 & 83 & 105 & 129 & 198 & $30-100$ & $100-300$ & $30-300$ & \multirow{8}{*}{$\begin{array}{l}\text { CCNC, AMAZE- } 08 \text {, } \\
\text { this study, entire } \\
\text { campaign }\end{array}$} \\
\hline & $D_{t}(\mathrm{~nm})$ & & 55 & 83 & 105 & 131 & 201 & $30-100$ & $100-300$ & $30-300$ & \\
\hline \multirow[t]{2}{*}{$\mathrm{CCN}$-active } & $\kappa_{a}$ & & 0.12 & 0.114 & 0.154 & 0.184 & 0.196 & 0.117 & 0.178 & 0.1536 & \\
\hline & $f_{n}$ & & 1 & 1 & 1 & 0.98 & 0.92 & 1 & 0.973 & 0.984 & \\
\hline \multirow[t]{2}{*}{$\mathrm{CCN}$-inactive } & $\kappa$ & & & & & 0.074 & 0.077 & & 0.077 & 0.077 & \\
\hline & $f_{n}$ & & & & & 0.0 .2 & 0.08 & & 0.08 & 0.08 & \\
\hline \multirow[t]{4}{*}{ All } & $\kappa_{t, \text { avg }}$ & & 0.120 & 0.114 & 0.154 & 0.182 & 0.186 & 0.117 & 0.174 & 0.151 & \\
\hline & $\kappa_{t}$ & & 0.119 & 0.112 & 0.153 & 0.177 & 0.187 & 0.116 & 0.172 & 0.150 & \\
\hline & $D_{a}(\mathrm{~nm})$ & & 55 & 85 & 106 & 135 & 221 & $30-100$ & $100-300$ & $30-300$ & \multirow{8}{*}{$\begin{array}{l}\text { CCNC, AMAZE-08, } \\
\text { this study, focus period }\end{array}$} \\
\hline & $D_{t}(\mathrm{~nm})$ & & 56 & 87 & 107 & 135 & 224 & $30-100$ & $100-300$ & $30-300$ & \\
\hline \multirow[t]{2}{*}{$\mathrm{CCN}$-active } & $\kappa_{a}$ & & 0.118 & 0.105 & 0.15 & 0.164 & 0.143 & 0.112 & 0.152 & 0.136 & \\
\hline & $f_{n}$ & & 1 & 1 & 1 & 0.99 & 0.88 & 1 & 0.960 & 0.976 & \\
\hline \multirow[t]{2}{*}{$\mathrm{CCN}$-inactive } & $\kappa$ & & & & & 0.074 & 0.077 & & 0.077 & 0.077 & \\
\hline & $f_{n}$ & & & & & 0.01 & 0.12 & & 0.12 & 0.12 & \\
\hline \multirow[t]{2}{*}{ All } & $\kappa_{t, \text { avg }}$ & & 0.118 & 0.105 & 0.150 & 0.163 & 0.135 & 0.112 & 0.149 & 0.134 & \\
\hline & $\kappa_{t}$ & & 0.115 & 0.100 & 0.148 & 0.161 & 0.137 & 0.108 & 0.150 & 0.132 & \\
\hline
\end{tabular}

hygroscopicity as the VLH particles observed by Vestin et al. $(2007 ; \kappa=0.077$ at $D=265 \mathrm{~nm})$, we have calculated $\kappa_{t \text {,avg }}$ values for the mixture of $\mathrm{CCN}$-active and -inactive particles observed by CCNC measurements in the same way as for the mixture of VLH, LH and MH particles observed in HTDMA measurements. For the entire campaign as well as for the focus period (and for the rest of the campaign, not listed), the

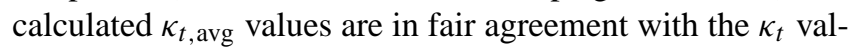
ues derived from 2-parameter $\mathrm{CDF}$ fits to the measured $\mathrm{CCN}$ efficiency spectra.

Roberts et al. (2002) reported integral CCN measurements, chemical composition data and $\mathrm{CCN}$ closure calculations for Amazonian wet-season aerosols as observed during LBA-CLAIRE-98 (March-April 1998). Based on Köhler model sensitivity studies they showed that the observed $\mathrm{CCN}$ properties were consistent with average mass fractions of $\sim 15 \%$ ammonium bisulfate and $\sim 40 \%$ watersoluble organics. Under the assumption of $\kappa_{\mathrm{AHS}} \approx 0.6$ and $\kappa_{\text {org }} \approx 0.1$ (Sect. 3.3), this would correspond to an average effective hygroscopicity parameter of $\sim 0.13$, which is consistent with the overall average $\kappa_{t}$,avg values calculated from the H-TDMA data of Vestin et al. $(\sim 0.15)$ and Zhou et al. $(\sim 0.11)$, and with the $\kappa_{t}$ and $\kappa_{t}$,avg values determined from our size resolved CCN measurements $(\sim 0.13$ for focus period, $\sim 0.15$ for entire campaign). 


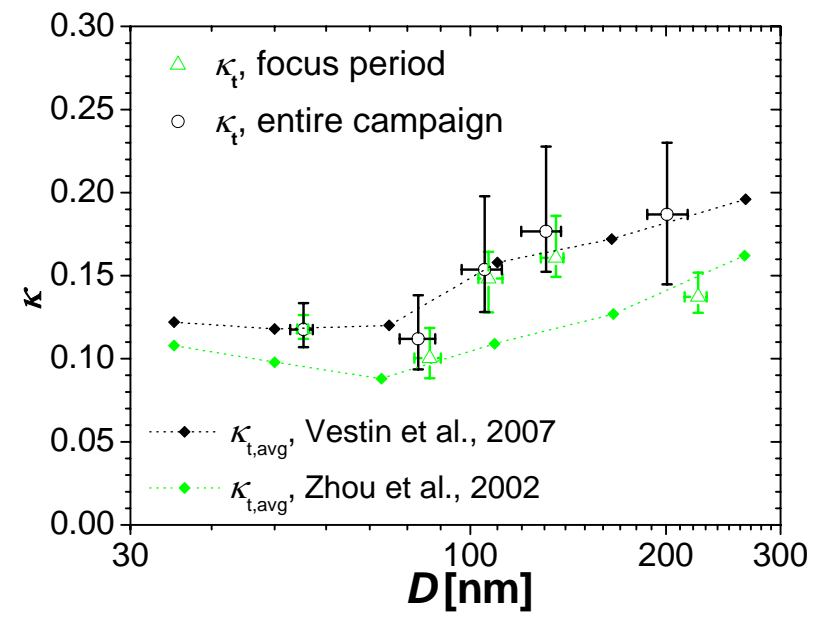

Fig. 5. Effective hygroscopicity parameters for the overall population of aerosol particles observed in pristine Amazonian rainforest air during AMAZE-08 and earlier campaigns during the wet season (CLAIRE 1998, Zhou et al., 2002; LBA-SMOCC 2002, Vestin et al., 2007). $\kappa_{t}$ was determined by 2-parameter CDF fits to the size-resolved CCN efficiency spectra measured in this study (median values for the entire campaign and for the focus period with error bars extending to upper and lower quartiles). $\kappa_{\mathrm{t}}$, avg was calculated from the HTDMA measurement results reported by Zhou et al., 2002 and Vestin et al., 2007 (campaign average values with connecting lines, Table 2).

As demonstrated by Rose et al. (2008b) for highly polluted megacity air and below for pristine rainforest air (Sect. 3.2.2), $\kappa_{t}$ is well suited for predicting number concentrations of $\mathrm{CCN}$ from atmospheric aerosol size distributions. Thus, the fair agreement of $\kappa_{t}$, avg and $\kappa_{t}$ shown in Table 2 and Fig. 5 indicates that the simple averaging approach taken for the comparison of hygroscopicity parameters derived from HTDMA and CCNC measurements is suitable for (approximately) describing the CCN activity of atmospheric aerosols - at least in Amazonia during the wet season. We suggest that the applicability of $\kappa_{t}$ and $\kappa_{t}$,avg for efficient comparison and description of the CCN activity of atmospheric aerosol particles should be tested by further investigations combining size-resolved CCNC, HTDMA and particle composition measurements at different locations and conditions (Rose et al., 2009).

Note, however, that the simple averaging approach and effective hygroscopicity parameters/proxies presented above are not meant to replace other more detailed approaches that attempt to resolve externally mixed groups of particles with different hygroscopic properties by more elaborate measurements and models. In fact, more detailed investigations should help to corroborate and/or improve the presented approximations.
Nevertheless, these or similar approximations appear to be not only suitable but also necessary for efficient description of the CCN activity of atmospheric aerosols in studies where only a limited amount of information is available or applicable. Not all measurement instruments, data sets and atmospheric or climate models can provide or process detailed information about aerosol composition and mixing state. Thus, parameters like $\kappa_{t}$ and $\kappa_{t}$,avg are likely to be useful not only for efficient comparison of different field measurement data sets as in the present study. They may also be useful for studies where only (approximate) aerosol particle concentrations and size distributions are available and applicable, e.g. from remote sensing and long-term monitoring data sets and for long-term climate model calculations (Anderson et al., 2009; Andreae, 2009; Kinne, 2009; Shinozuka et al., 2009; and references therein).

\subsection{CCN size distributions and number concentrations}

\subsubsection{Measurement results}

Figure 6 shows average size distributions of total aerosol particles $(\mathrm{CN})$ and of $\mathrm{CCN}$ at different supersaturation levels for the entire campaign, for the focus period, and for the rest of the campaign, respectively. The corresponding average values of integral $\mathrm{CN}$ number concentration for particles larger than $30 \mathrm{~nm}\left(N_{\mathrm{CN}, 30}\right), \mathrm{CCN}$ number concentrations $\left(N_{\mathrm{CCN}, S}\right)$, and $\mathrm{CCN}$ efficiencies $\left(N_{\mathrm{CCN}, S} / N_{\mathrm{CN}, 30}\right)$ are summarized in Tab. 1, and their statistical distributions are illustrated in the online supplement (Figs. S7-S8: http://www.atmos-chem-phys.net/ 9/7551/2009/acp-9-7551-2009-supplement.pdf). Throughout the campaign, the observed $\mathrm{CN}$ number size distributions exhibited pronounced Aitken and accumulation modes around $\sim 70 \mathrm{~nm}$ and $\sim 180 \mathrm{~nm}$, respectively. Best-fit parameters of bimodal lognormal size distribution functions fitted to the median $\mathrm{CN}$ size distributions as displayed in Fig. 6 are given in Table 3. The median $\mathrm{CN}$ concentrations were similar for the focus period and for the rest of the campaign $\left(N_{\mathrm{CN}, 30} \approx 200 \mathrm{~cm}^{-3}\right)$, but the relative standard deviations were much higher during the rest of the campaign $(\sim 30 \%$ vs. $\sim 100 \%$, Table 1$)$, reflecting shortterm events with strongly elevated $\mathrm{CN}$ concentrations (up to $\sim 2 \times 10^{3} \mathrm{~cm}^{-3}$, Fig. 7a).

At low supersaturation $(S=0.10 \%)$, the median $\mathrm{CCN}$ number concentration and integral $\mathrm{CCN}$ efficiency $\left(N_{\mathrm{CCN}, S} / N_{\mathrm{CN}, 30}\right)$ were about three times lower for the focus period $\left(14 \mathrm{~cm}^{-3}, 0.06\right)$ than for the rest of the campaign $\left(43 \mathrm{~cm}^{-3}, 0.18\right)$, which is due to a decrease in size and hygroscopicity of the accumulation mode particles (Fig. 6b vs. 6c). In contrast, the median value of $N_{\mathrm{CCN}, S}$ and $N_{\mathrm{CCN}, S} / N_{\mathrm{CN}, 30}$ at high supersaturation $(S=0.82 \%)$ were higher during the focus period $\left(205 \mathrm{~cm}^{-3}, 0.78\right)$ than during the rest of the campaign $\left(105 \mathrm{~cm}^{-3}, 0.75\right)$, which is mostly 

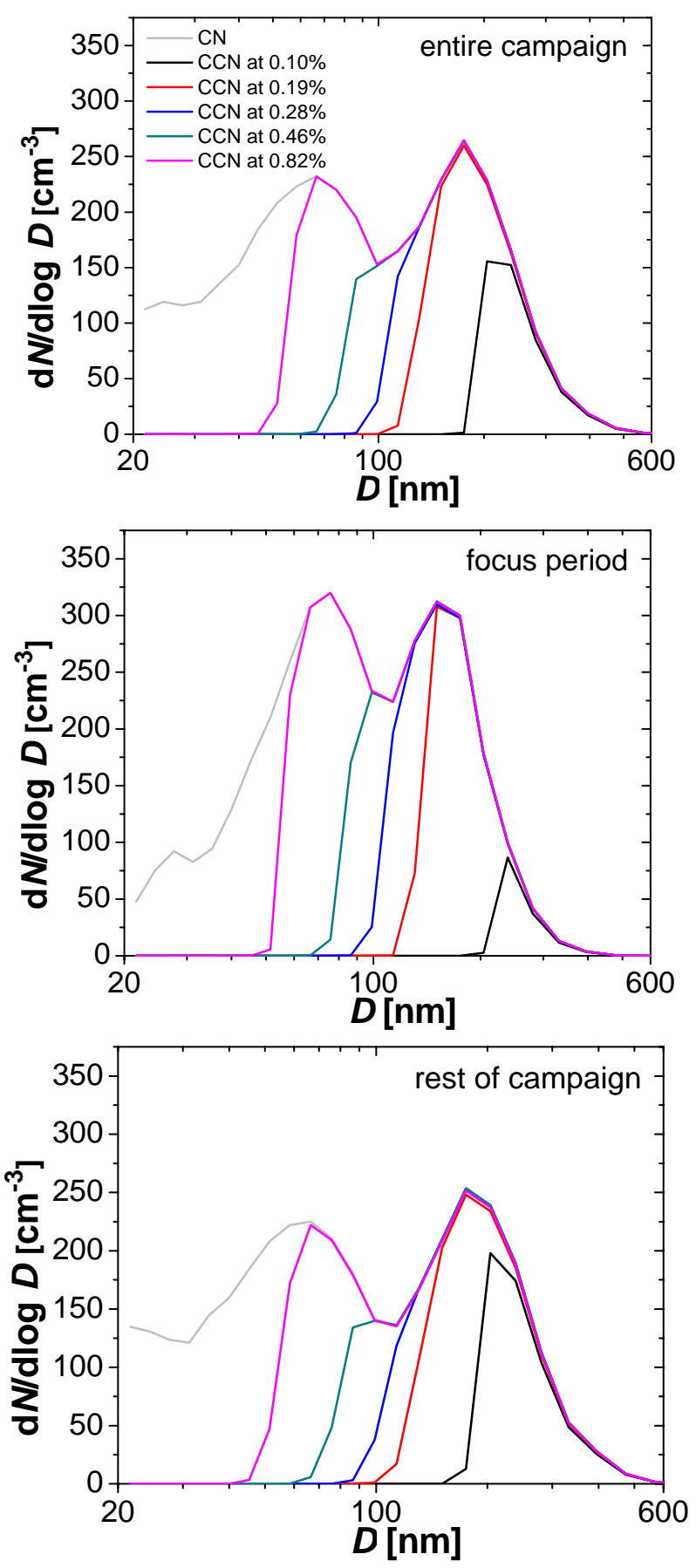

Fig. 6. Number size distributions of total aerosol particles $(\mathrm{CN})$ and of cloud condensation nuclei $(\mathrm{CCN})$ at different supersaturations ( $S=0.10-0.82 \%$ ) averaged over the entire campaign (a), over the focus period (b), and over the rest of the campaign (c). The CCN size distributions were calculated by multiplying the median $\mathrm{CN}$ size distributions (grey lines) with median CCN efficiency spectra (3-parameter CDF fits). due to an increase in the concentration of Aitken mode particles (Fig. 6b vs. 6c).

Figure 7 illustrates the temporal variability of $\mathrm{CN}$ and $\mathrm{CCN}$ number concentrations with characteristic ranges of $\sim 10^{2}-10^{3} \mathrm{~cm}^{-3}$ for $N_{\mathrm{CN}, 30}, \sim 50-300 \mathrm{~cm}^{-3}$ for $N_{\mathrm{CCN}, 0.82}$, and $\sim 5-100 \mathrm{~cm}^{-3}$ for $N_{\mathrm{CCN}, 0.10}$, corresponding to integral $\mathrm{CCN}$ efficiencies in the range of $\sim 0.5-0.9$ for $N_{\mathrm{CCN}, 0.82} / N_{\mathrm{CN}, 30}$ and $\sim 0.05-0.4$ for $N_{\mathrm{CCN}, 0.10} / N_{\mathrm{CN}, 30}$, respectively.

Averaged over the campaign, the $\mathrm{CN}$ and $\mathrm{CCN}$ number concentrations observed during AMAZE-08 were up to $\sim 80 \%$ lower than those observed in earlier measurements of pristine Amazonian rainforest air, but the integral CCN efficiencies generally agreed to within $\sim 20 \%$ (Roberts et al., 2001, 2002; Andreae et al., 2004; Rissler et al., 2004; Vestin et al., 2007).

Compared to highly polluted megacity regions (Rose et al., 2008b; Wiedensohler et al., 2008), the CN and CCN number concentrations observed during AMAZE-08 were two orders of magnitude lower, but the integral $\mathrm{CCN}$ efficiencies were still similar and consistent with the global average values reported by Andreae $\left(2009, N_{\mathrm{CCN}, 0.4} / N_{\mathrm{CN}, 10} \approx 0.4\right)$.

\subsubsection{Approximations and model predictions}

In analogy to Rose et al. (2008b) we compare different approaches for the approximation/prediction of CCN concentration as a function of water vapor supersaturation, particle number concentration, size distribution and hygroscopicity: (1) a classical power law approach relating $N_{\mathrm{CCN}, S}$ to a constant average value of $N_{\mathrm{CCN}, 1}$, i.e. to the average CCN concentration at $S=1 \%$; (2) a modified power law approach relating $N_{\mathrm{CCN}, S}$ to the concentration of aerosol particles with $D>30 \mathrm{~nm}\left(N_{\mathrm{CN}, 30}\right)$; and (3) a $\kappa$-Köhler model approach relating $N_{\mathrm{CCN}, S}$ to the aerosol particle size distribution $\left(\mathrm{d} N_{\mathrm{CN}} / \mathrm{d} \log D\right)$ and effective hygroscopicity. For all data points obtained during the campaign, the model predictions were compared with the measurement results, and the mean values of the relative deviations are summarized in Table 4.

\section{Classical power law with constant average $N_{\mathrm{CCN}, 1}$}

Figure 8 shows the median values of $N_{\mathrm{CCN}, S}$ plotted against $S$ with power law fits of the form $N_{\mathrm{CCN}, S}=N_{\mathrm{CCN}, 1}$ - $(S / 1 \%)^{k}$ (Pruppacher and Klett, 1997; OriginPro 8 software, Levenberg-Marquardt algorithm). The best fit values obtained for the $\mathrm{CCN}$ number concentration at $S=1 \%$ (median $N_{\mathrm{CCN}, 1}=201 \mathrm{~cm}^{-3}$, mean $N_{\mathrm{CCN}, 1}=238 \mathrm{~cm}^{-3}$ ) are among the lowest values reported from CCN measurements in pristine environments, and the best fit values for the exponent (median $k=0.63$, mean $k=0.70$ ) are in the middle of the range reported for other continental locations (0.4-0.9; Pruppacher and Klett, 1997; Andreae, 2008). The mean relative deviations of the individual measurement data points 
Table 3. Best-fit parameters of bimodal lognormal size distribution functions fitted to the observed median size distributions of aerosol particles $(\mathrm{CN})$ as displayed in Fig. 6 for the entire campaign, for the pristine focus period, and for the rest of the campaign: integral number concentration $\left(N_{\mathrm{CN}}\right)$, count median or geometric mean diameter $\left(D_{g}\right)$, and geometric standard deviation $\left(\sigma_{g}\right)$ for each mode $($ Aitken and accumulation). The concentration values are normalized to a reference state of $273 \mathrm{~K}$ and $1000 \mathrm{hPa}$.

\begin{tabular}{llrrr}
\hline Period & Mode & $N_{\mathrm{CN}}\left[\mathrm{cm}^{-3}\right]$ & $D_{g}[\mathrm{~nm}]$ & $\sigma_{g}$ \\
\hline \multirow{2}{*}{ Entire campaign } & Aitken & 97 & 57.3 & 1.49 \\
& Accumulation & 95 & 168 & 1.43 \\
\hline Focus period & Aitken & 90 & 66.6 & 1.32 \\
& Accumulation & 111 & 150 & 1.43 \\
\hline \multirow{2}{*}{ Rest of campaign } & Aitken & 86 & 57.7 & 1.43 \\
& Accumulation & 96 & 173 & 1.43 \\
\hline
\end{tabular}
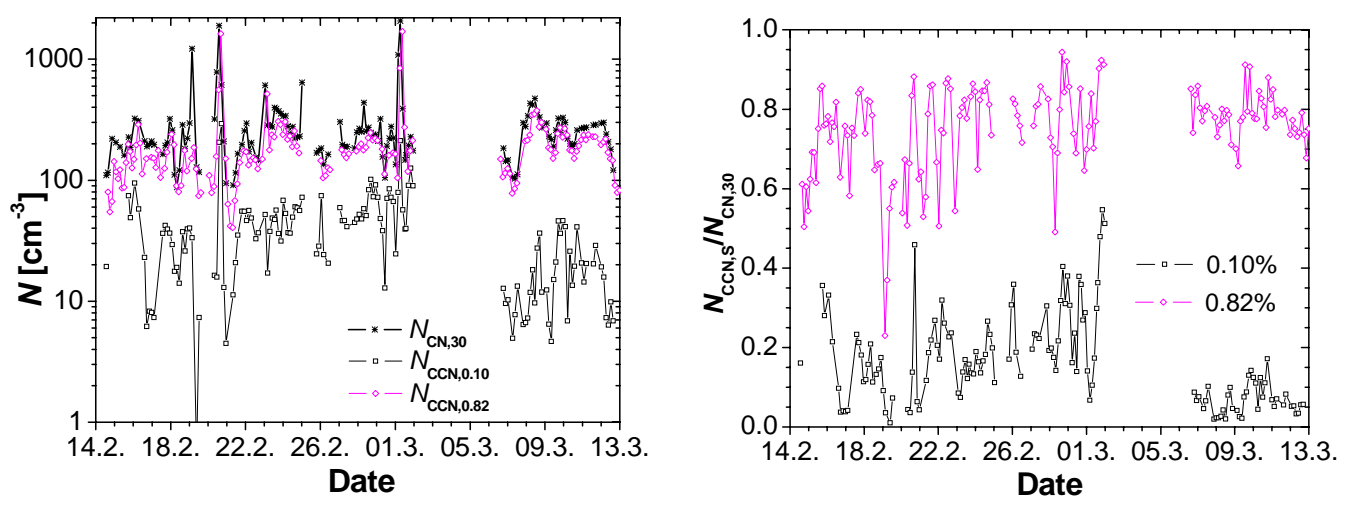

Fig. 7. Time series of the number concentrations of aerosol particles with $D>30 \mathrm{~nm}\left(N_{\mathrm{CN}, 30}\right)$ and cloud condensation nuclei $\left(N_{\mathrm{CCN}, S}\right)$, and of the integral $\mathrm{CCN}$ efficiencies $\left(N_{\mathrm{CCN}, S} / N_{\mathrm{CN}, 30}\right)$ at different levels of supersaturation $(S=0.10 \%$ and $0.82 \%)$ plotted against the date in February-March 2008 (UTC).

from the average power laws were in the range of $40-60 \%$ for $S=0.19-0.82 \%$ and as high as $\sim 200 \%$ for $S=0.10 \%$ (Table 5), which is similar to the results obtained by Rose et al. (2008b) for highly polluted air.

\section{Modified power law with variable $N_{\mathrm{CN}, 30}$}

Figure 9 shows the measurement values of $N_{\mathrm{CCN}, S}$ plotted against $N_{\mathrm{CN}, 30}$ and power law fits of the form $N_{\mathrm{CCN}, S}=N_{\mathrm{CN}, 30} \cdot(s)^{-q}$ with $s=1+S /(100 \%)$ (OriginPro 8 software, Levenberg-Marquardt algorithm; Pruppacher and Klett, 1997). The best fit values obtained for the exponent $q$ and the corresponding correlation coefficients are listed in Table 5, and the results are similar to those obtained by Rose et al. (2008b). At high supersaturations $(S \geq 0.46 \%), N_{\mathrm{CCN}, S}$ was fairly well correlated to $N_{\mathrm{CN}, 30}\left(R^{2}=0.65-0.90\right)$ and the mean relative deviations between the MPL fits and the individual measurement values of $N_{\mathrm{CCN}, S}$ were $<40 \%$. At low supersaturations $(S \leq 0.28 \%)$ the correlation coefficients were small $\left(R^{2} \leq 0.5\right)$, but the mean relative deviations were still less than in the CPL approach based on a constant average values of $N_{\mathrm{CCN}, 1}$.

\section{$\kappa$-Köhler model with variable $\mathrm{CN}$ size distributions}

In Fig. 10 predicted $\mathrm{CCN}$ number concentrations $\left(N_{\mathrm{CCN}, S, p}\right)$ that were obtained with the $\kappa$-Köhler model and different hygroscopicity parameters are plotted against measurement values of $N_{\mathrm{CCN}, S}$. For each data point, $N_{\mathrm{CCN}, S, p}$ was calculated by integrating the measured $\mathrm{CN}$ size distribution above the critical dry particle diameter for $\mathrm{CCN}$ activation that corresponds to the given values of $\kappa$ and $S$ as detailed in Rose et al. (2008b).

As illustrated in Fig. 10a, the measured and predicted values of $N_{\mathrm{CCN}, S}$ are generally in good agreement, when for each data point $\kappa_{t}$ is taken from the individual $\mathrm{CCN}$ efficiency spectrum measured in parallel to the $\mathrm{CN}$ size distribution. With this approach, the mean relative deviation averaged over all supersaturations was only $6 \%$, and the overall mean bias of the model values was $+5 \%$ (Table 4 ). The agreement confirms that $\kappa_{t}$ is a suitable proxy for the effective hygroscopicity and CCN activity of the investigated ensemble of aerosol particles, including $\mathrm{CCN}$-active and - inactive particles as proposed and demonstrated by Rose et al. (2008b). At $S=0.10\left(M A F_{f} \approx 0.9\right)$, the mean deviation and bias were 
Table 4. Characteristic deviations between measured $\mathrm{CCN}$ number concentrations $\left(N_{\mathrm{CCN}, S}\right)$ and $\mathrm{CCN}$ number concentrations predicted by different model approaches $\left(N_{\mathrm{CCN}, S, p}\right)$ : arithmetic mean values of the relative bias $\left(\Delta_{\mathrm{bias}} N_{\mathrm{CCN}, S}=\left(N_{\mathrm{CCN}, S, p}-N_{\mathrm{CCN}, S}\right) / N_{\mathrm{CCN}, S}\right)$ and of the total relative deviation $\left(\Delta_{\mathrm{dev}} N_{\mathrm{CCN}, S}=\left|N_{\mathrm{CCN}, S, p}-N_{\mathrm{CCN}, S}\right| / N_{\mathrm{CCN}, S}\right.$, including systematic and statistical errors). CPL and MPL are the classical and modified power law approaches. With regard to the $\kappa$-Köhler model approach, " $\kappa_{a}$ variable", " $\kappa_{t}$ variable", and " $\kappa_{p}$ variable" stand for the effective hygroscopicity parameters derived from individual CCN efficiency spectra (3- and 2-parameter CDF fits) and from concurrent AMS measurements, respectively. The constant $\kappa$ values are the campaign median of and the approximate global average values for continental aerosols, respectively. The expression "const. avg. SD from AMAZE-08" stands for model calculations using the campaign median particle size distribution, and "const. remote cont. SD from S\&P2006" stands for model calculations using the generic remote continental size distribution listed by Seinfeld and Pandis (2006). $n$ is the number of data points.

\begin{tabular}{|c|c|c|c|c|c|c|c|c|c|c|c|c|c|c|c|c|c|c|c|}
\hline \multirow[t]{2}{*}{$S[\%]$} & \multicolumn{2}{|c|}{ CPL } & \multicolumn{2}{|c|}{ MPL } & \multicolumn{2}{|c|}{$\kappa_{t}$ variable } & \multicolumn{2}{|c|}{$\kappa_{a}$ variable } & \multicolumn{2}{|c|}{$\kappa_{p}$ variable } & \multicolumn{2}{|c|}{$\kappa=0.15$} & \multicolumn{2}{|c|}{$\kappa=0.3$} & \multicolumn{2}{|c|}{$\begin{array}{c}\kappa_{a} \text { variable with } \\
\text { const. avg. SD } \\
\text { from AMAZE-08 }\end{array}$} & \multicolumn{2}{|c|}{$\begin{array}{c}\kappa_{a} \text { variable with } \\
\text { const. remote cont. SD } \\
\text { from S\&P2006 }\end{array}$} & \multirow[t]{2}{*}{$n$} \\
\hline & $\begin{array}{l}\text { bias } \\
{[\%]}\end{array}$ & $\begin{array}{l}\mathrm{dev} \\
{[\%]}\end{array}$ & $\begin{array}{l}\text { bias } \\
{[\%]}\end{array}$ & $\begin{array}{l}\mathrm{dev} \\
{[\%]}\end{array}$ & $\begin{array}{l}\text { bias } \\
{[\%]}\end{array}$ & $\begin{array}{l}\mathrm{dev} \\
{[\%]}\end{array}$ & $\begin{array}{l}\text { bias } \\
{[\%]}\end{array}$ & $\begin{array}{l}\mathrm{dev} \\
{[\%]}\end{array}$ & $\begin{array}{l}\text { bias } \\
{[\%]}\end{array}$ & $\begin{array}{l}\mathrm{dev} \\
{[\%]}\end{array}$ & $\begin{array}{l}\text { bias } \\
{[\%]}\end{array}$ & $\begin{array}{l}\mathrm{dev} \\
{[\%]}\end{array}$ & $\begin{array}{l}\text { bias } \\
{[\%]}\end{array}$ & $\begin{array}{l}\mathrm{dev} \\
{[\%]}\end{array}$ & $\begin{array}{l}\text { bias } \\
{[\%]}\end{array}$ & $\begin{array}{l}\mathrm{dev} \\
{[\%]}\end{array}$ & $\begin{array}{l}\text { bias } \\
{[\%]}\end{array}$ & $\begin{array}{l}\mathrm{dev} \\
{[\%]}\end{array}$ & \\
\hline 0.10 & +201.3 & 220.9 & +99.5 & 132.3 & +10.5 & 14.3 & +16.7 & 18 & +21.2 & 26.8 & -3.7 & 29.7 & +110.2 & 111.3 & +94.8 & 124.4 & +1454 & 1454 & 132 \\
\hline 0.19 & +12.6 & 51.1 & +15.0 & 38.9 & +3.2 & 4.1 & +4.2 & 4.6 & +5.0 & 10.7 & -1.3 & 11.8 & +24.7 & 24.9 & +23.2 & 51 & +1652 & 1652 & 158 \\
\hline 0.28 & +18.3 & 52.8 & +20.6 & 39.3 & +4.5 & 4.9 & +4.4 & 5.0 & +10.7 & 11.8 & +5.4 & 9.9 & +26.5 & 26.6 & +21.5 & 50.6 & +1792 & 1792 & 155 \\
\hline 0.46 & +24.0 & 46.8 & +19.2 & 35.9 & +2.1 & 4.5 & +3.3 & 4.2 & +22.6 & 22.6 & +16.7 & 17.3 & +40.4 & 40.4 & +12.3 & 42 & +1873 & 1873 & 151 \\
\hline 0.82 & +25.5 & 45.7 & +15.6 & 30.6 & +3.9 & 4.1 & +3.4 & 3.5 & +14.7 & 14.8 & +10.5 & 10.1 & +24.0 & 24 & +7.5 & 39.1 & +1732 & 1732 & 155 \\
\hline All & +56.0 & 83.3 & +33.6 & 55.3 & +4.6 & 6.2 & +6.2 & 6.9 & +14.1 & 16.8 & +4.1 & 14.7 & +44.9 & 45.4 & +29.6 & 58.7 & +1580 & 1580 & 751 \\
\hline
\end{tabular}

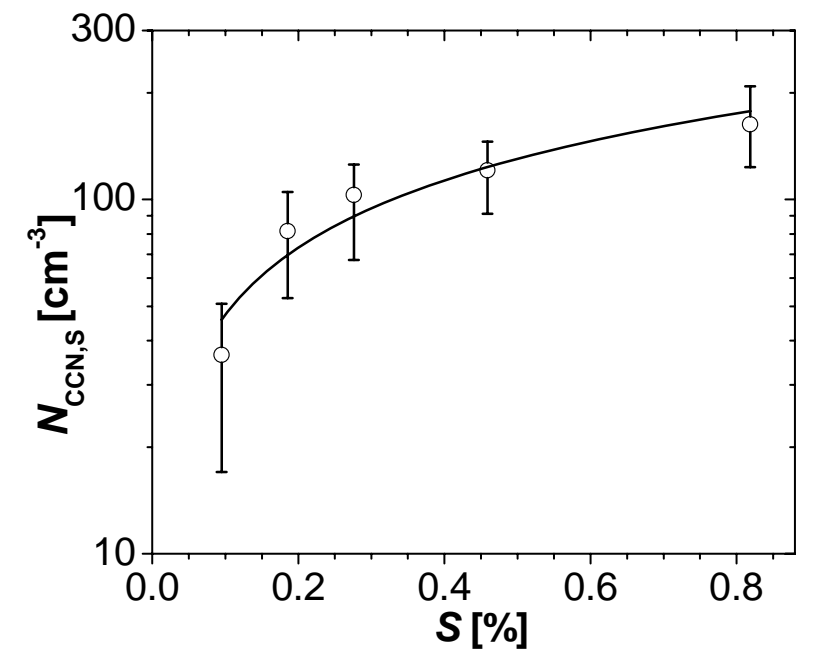

Fig. 8. CCN number concentrations $\left(N_{\mathrm{CCN}, S}\right)$ plotted against water vapor supersaturation $(S)$. The data points are median values, and the error bars extend to lower and upper quartiles for the entire campaign. The black line is a power law fit of the form $N_{\mathrm{CCN}, S}=N C C N, 1 .(S /(1 \%)) k$ with the best fit parameters $N_{\mathrm{CCN}, 1}=201 \mathrm{~cm}_{3}$ and $k=0.63\left(R^{2} 0.91, n=5\right)$.

highest $(14 \%,+10 \%$; Table 4$)$, indicating that the effect of external mixing between $\mathrm{CCN}$-active and -inactive particles is not fully captured by $\kappa_{t}$. Nevertheless, the results obtained with $\kappa_{t}$ were clearly better than with $\kappa_{a}$, which represents the effective hygroscopicity of the $\mathrm{CCN}$-active particles only and thus leads to higher mean deviation and bias $(18 \%,+17 \%$; Table 4). At $S=0.19-0.82 \%$ where $M A F_{f} \approx 1$ and $\kappa_{a} \approx \kappa_{t}$, the results obtained with individual $\kappa_{a}$ values were nearly the same as with individual $\kappa_{t}$, and thus the overall mean bias and deviation were only slightly higher (+6\%, 7\%; Table 4).

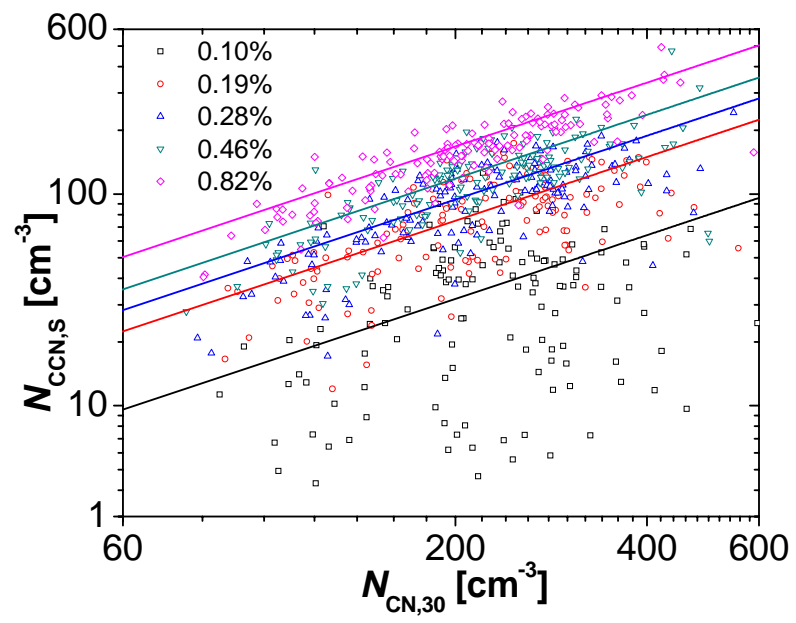

Fig. 9. $\mathrm{CCN}$ number concentrations $\left(N_{\mathrm{CCN}, S}\right)$ observed at different supersaturations $(S=0.10-0.82 \%)$ plotted against the number concentration of aerosol particles with $\mathrm{D}>30 \mathrm{~nm}\left(N_{\mathrm{CN}, 30}\right)$. The lines are power law fits of the form $N_{\mathrm{CCN}, S}=N_{\mathrm{CN}, 30} .(s)^{-q}$; best fit parameters are given in Table 5.

Fair agreement between measured and predicted CCN number concentrations was also achieved when the campaign median value of $\kappa \approx 0.15$ was used for the calculation of $N_{\mathrm{CCN}, S, p}$. With this constant average hygroscopicity parameter, the mean relative deviations were about twice as high but the bias was not higher than when using variable $\kappa_{t}$ or $\kappa_{a}$ values (15\%, +4\%, Table 4; Fig. 10b).

Figure 10c illustrates the results obtained with composition-based effective hygroscopicity parameters $\kappa_{p}$ derived from online aerosol mass spectrometry (AMS) data as detailed below (Sect. 3.3). With these parameters, the 

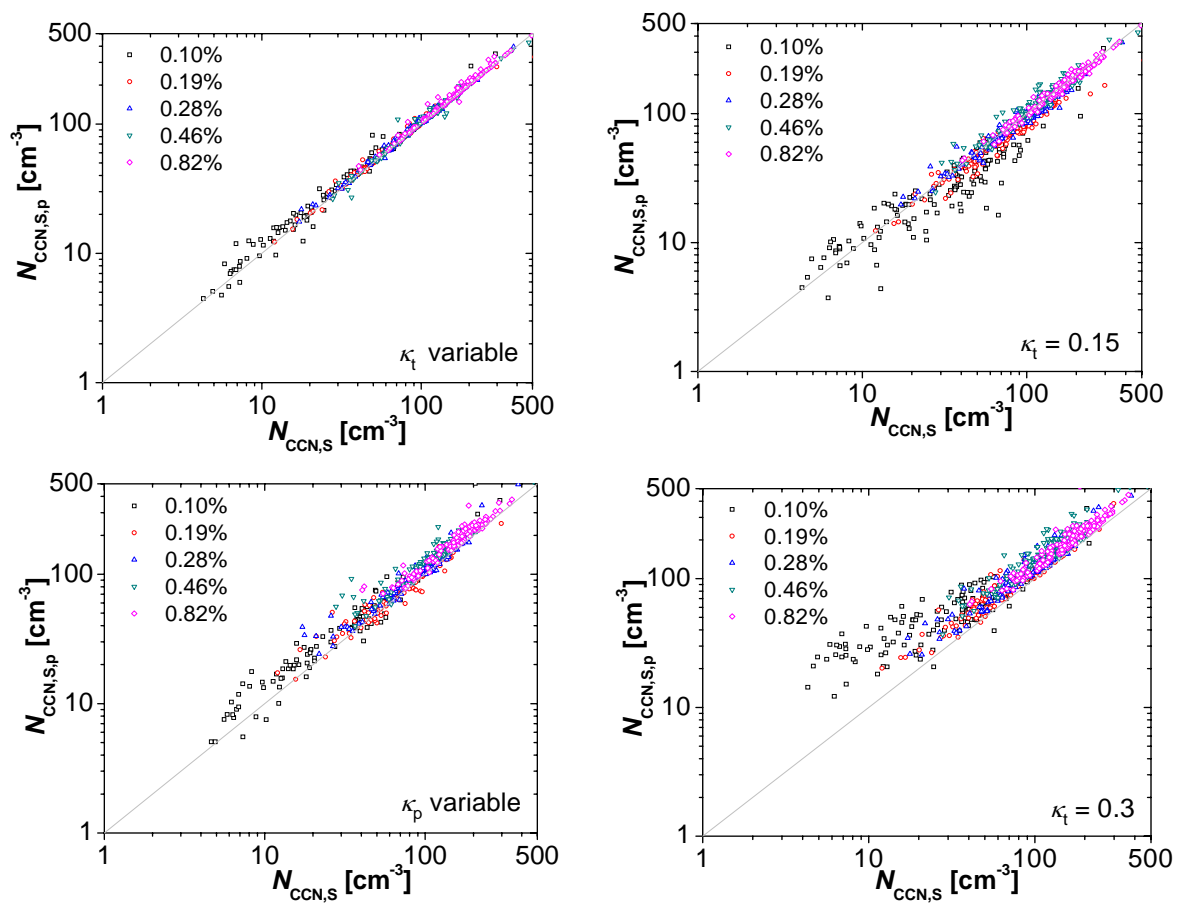

Fig. 10. Predicted vs. measured CCN number concentrations $\left(N_{\mathrm{CCN}, S, p}\right.$ vs. $\left.N_{\mathrm{CCN}, S}\right)$. Predictions are based on the $\kappa$-Köhler model approach using different types of effective hygroscopicity parameters: (a) variable values of $\kappa_{t}$ as derived from the individual CCN efficiency spectra; (b) constant campaign median value $\kappa=0.15$; (c) variable values of $\kappa_{p}$ predicted with organic and inorganic mass fractions determined by AMS; and (d) constant approximate global average value of $\kappa=0.3$.

Table 5. Best fit parameters for the modified power law (MPL): $N_{\mathrm{CCN}, \mathrm{S}}=N_{\mathrm{CN}, 30}(s)^{-q} \cdot R^{2}$ is the correlation coefficient, and $n$ is the number of data points.

\begin{tabular}{ccccc}
\hline$S[\%]$ & $s$ & $q$ & $R^{2}$ & $n$ \\
\hline 0.10 & 1.0010 & 2031 & 0.05 & 132 \\
0.19 & 1.0019 & 586 & 0.32 & 158 \\
0.28 & 1.0028 & 303 & 0.53 & 155 \\
0.46 & 1.0046 & 135 & 0.65 & 151 \\
0.82 & 1.0082 & 33 & 0.90 & 155 \\
\hline
\end{tabular}

mean relative deviations were similar to the ones obtained with the campaign average values of $\kappa(17 \%)$ but the bias was substantially higher $(+14 \%$, Table 4$)$, which can be explained by the use of integral rather than size-resolved AMS data (overestimation of inorganic fraction for small particles activated at high $S$, see Sect. 3.3).

Assuming a constant approximate global average hygroscopicity parameter $\kappa \approx 0.3$, as observed at other continental locations (Andreae and Rosenfeld, 2008; Rose et al., 2008b; Pöschl et al., 2009a; and references therein) in agreement with global model simulations (Tsigaridis et al., 2006; Kreidenweis et al., 2009), led to substantial overestimations of $N_{\mathrm{CCN}, S}$. The overall mean deviation was $\sim 45 \%$, ranging between $\sim 24 \%$ at high $S$ and $\sim 110 \%$ at low $S$ (Table 4, Fig. 10d). Note, however, that the bias and deviations of this approach were on average still smaller than with the power law approach based on the campaign average fit values of $N_{\mathrm{CCN}, 1}$. Time series and statistical distributions of $N_{\mathrm{CCN}, S, p} / N_{\mathrm{CCN}, S}$ corresponding to the data points of Fig. 10 are shown in the online supplement (Figs. S9-S10: http://www.atmos-chem-phys.net/9/ 7551/2009/acp-9-7551-2009-supplement.pdf).

Clearly, the calculation of $\mathrm{CCN}$ number concentrations with $\kappa=0.3$ cannot capture the short-term variability and leads to a systematic over prediction in the investigated tropical rainforest environment with very high proportion of organic particulate matter (Sect. 3.3) and correspondingly low effective hygroscopicity of the aerosol particles. Nevertheless, we consider it remarkable that the assumption of an approximate global average effective hygroscopicity parameter of $\kappa \approx 0.3$ (Andreae and Rosenfeld, 2008; Kreidenweis et al., 2009; Pöschl et al., 2009a) enables the prediction of $\mathrm{CCN}$ number concentrations from aerosol particle number size distributions over a range of three orders of magnitude $\left(\sim 10^{1}-10^{4} \mathrm{~cm}^{-3}\right)$ going from pristine tropical rainforest air to highly polluted megacity regions (Rose et al., 2008b; Wiedensohler et al., 2009) with relative deviations exceeding $\sim 50 \%$ only at very low water vapor supersaturations $(\leq 0.1 \%)$ and particle number concentrations $\left(\leq 100 \mathrm{~cm}^{-3}\right)$. 
$\kappa$-Köhler model with constant $\mathrm{CN}$ size distributions

To test the relative importance of aerosol particle size distribution and hygroscopicity for the variability of $N_{\mathrm{CCN}, S}$, we performed additional Köhler model calculations in which the effective hygroscopicity parameters were allowed to vary (variable $\kappa_{t}$ from the fitting of measured $\mathrm{CCN}$ efficiency spectra) while the $\mathrm{CN}$ size distribution was kept constant. In analogy to the above sensitivity studies using constant campaign average and approximate global average values of the effective hygroscopicity parameter $(\kappa \approx 0.15$ and $\kappa \approx 0.3$, respectively), we used the campaign average size distribution (Fig. 6a, Table 3) and a generic remote continental size distribution as listed in Seinfeld and Pandis (2006, Table 8.3, based on Jaenicke, 1993) with lognormal modes defined by the following geometric mean diameters, standard deviations and number concentrations, respectively: $D_{g, 1}=20 \mathrm{~nm}, \sigma_{g, 1}=1.449, N_{\mathrm{CN}, 1}=3200 \mathrm{~cm}^{-3}$ and $D_{g, 2}=116 \mathrm{~nm} ; \sigma_{g, 2}=1.648, N_{\mathrm{CN}, 2}=2900 \mathrm{~cm}^{-3}$.

With the constant campaign average size distribution (Fig. 6a, Table 3) and variable $\kappa$, the mean relative deviation between measured and predicted $\mathrm{CCN}$ concentrations $(\sim 60 \%)$ was by a factor of $\sim 4$ higher than with the constant campaign average value of $\kappa \approx 0.15$ and variable size distribution $(\sim 15 \%$, Table 4$)$. Assuming a constant generic size distribution for remote continental areas with variable $\kappa$, the mean relative deviation between measured and predicted CCN concentrations $(\sim 1600 \%)$ was by a factor of $\sim 27$ higher than under the assumption of an approximate global average value of $\kappa \approx 0.3$ with variable size distribution $(\sim 1600 \%$, Table 4$)$.

The comparison of measured and modeled CCN concentrations clearly demonstrates that the variability of $\mathrm{CCN}$ concentrations is much stronger influenced by the variability of aerosol particle number concentration and size distribution than by the variability of aerosol chemical composition and hygroscopicity. This applies for the temporal variations during the AMAZE-08 campaign (factor $\sim 4$ ) as well as for spatial/geographic variations between central Amazonia during the wet season and other remote continental regions (factor $\sim 27$ ).

The above sensitivity studies and the similar integral CCN efficiencies observed in pristine rainforest, highly polluted megacities and other remote and polluted regions around the world (Sect. 3.2.1; Andreae, 2009) confirm earlier studies suggesting that aerosol particle number and size are the major predictors for the variability of the $\mathrm{CCN}$ concentration in continental boundary layer air, followed by particle composition and hygroscopicity as relatively minor modulators (Feingold et al., 2001; Feingold, 2003; Dusek et al., 2006; Ervens et al., 2007; Andreae and Rosenfeld, 2008; Rose et al., 2008b; Anderson et al., 2009; Feingold and Siebert, 2009; Kreidenweis et al., 2009; Pöschl et al., 2009a).
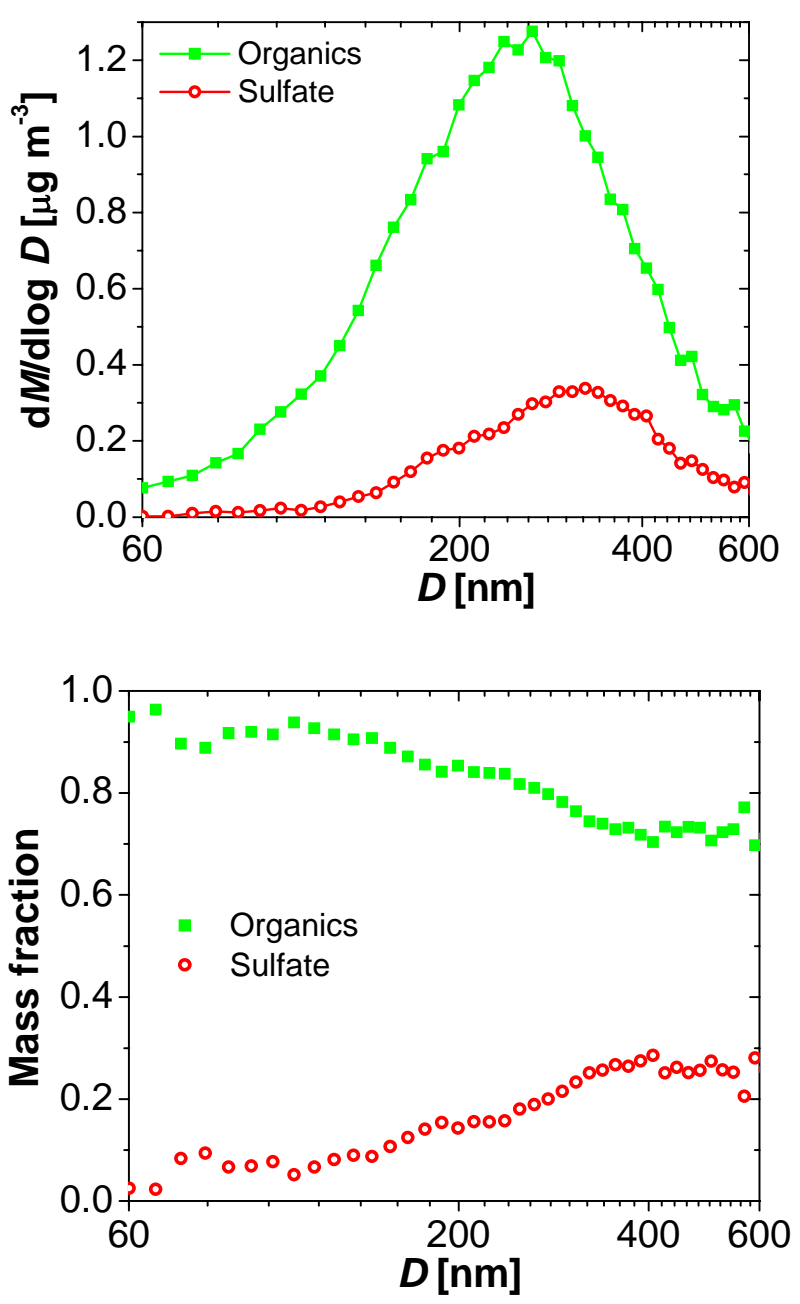

Fig. 11. Mass size distributions (a) and corresponding mass fractions (b) of organics and sulfate determined by aerosol mass spectrometry (AMS) averaged over the entire campaign (CCN measurement period). The diameter values $(D)$ are approximate mobility equivalent diameters calculated by division of the AMS vacuum aerodynamic diameter through 1.4 (dimensionless density scaling factor).

\subsection{Aerosol chemical composition and effective hygroscopicity}

A detailed presentation and discussion of the AMS measurement results will be given by Chen et al. (2009). Here we only address the relations between AMS and CCN measurement results.

Figure 11 shows the average aerosol mass size distribution of organic compounds and sulfate and the corresponding mass fractions $\left(f_{\text {org }}, f_{\mathrm{SO} 4}\right)$ as determined by AMS measurements performed in parallel to the $\mathrm{CCN}$ measurements. The concentrations and mass fractions of other aerosol constituents measured by the AMS were much smaller (ammonium, nitrate, chloride: $f_{\mathrm{NH} 4} \approx 3 \%, f_{\mathrm{NO} 3} \approx 1 \%, f_{\mathrm{Cl}}<1 \%$ ). 


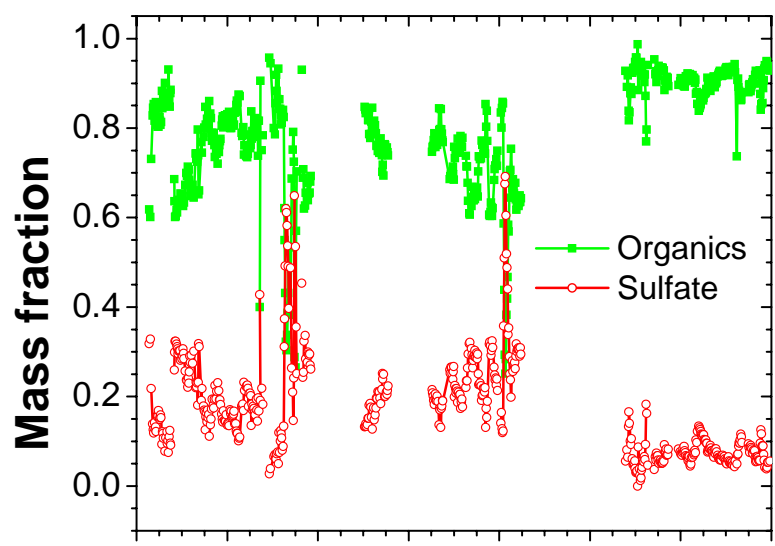

14.2. 18.2. 22.2. 26.2. 01.3. 05.3. 09.3. 13.3. Date

Fig. 12. Time series of organic and sulfate mass fractions determined by integral AMS measurements, averaged over corresponding CCN measurement intervals, and plotted against the date in February-March 2008 (UTC).

In order to make the size-resolved AMS and CCN measurement results directly comparable, Fig. 11 is based on approximate mobility equivalent diameters that have been calculated by division of the AMS vacuum aerodynamic diameter through a density scaling factor of 1.4 (Sect. 2.4; Chen et al., 2009). On the mobility diameter scale, the organic mass size distribution peaks slightly above $\sim 200 \mathrm{~nm}$ with a maximum value of $\sim 1.1 \mu \mathrm{g} \mathrm{m}^{-3}$ per logarithmic decade of particle diameter, while the sulfate size distribution peaks slightly below $\sim 300 \mathrm{~nm}$ with a maximum value of only $\sim 0.3 \mu \mathrm{g} \mathrm{m}^{-3}$. Accordingly, the mass fraction of sulfate increases from $\sim 0.1$ at $D<100 \mathrm{~nm}$ to $\sim 0.3$ at $D \geq 200 \mathrm{~nm}$.

This average size dependence of chemical composition is in agreement with the average size dependence of effective hygroscopicity reported above. As illustrated in Fig. 3, the observed increase of $\kappa$ with $D$ can be approximately described with the parameterization derived and used below for predicting the temporal variability of $\kappa$ as a function of $f_{\text {org }}$ and $f_{\text {inorg }} \approx f_{\mathrm{SO} 4}$ (Eq. 3 ).

Figure 12 shows the time series of organic and sulfate mass fractions derived from integral AMS measurements, with the organic mass fraction varying mostly in the range of $0.65-$ 0.95. Comparison with Fig. $4 \mathrm{~b}$ reveals that the highest organic mass fractions coincided with the lowest $\kappa$ values observed at $S=0.10 \%$, i.e. for accumulation mode particles with $D \approx 200 \mathrm{~nm}$. During the focus period in particular, the organic mass fraction was much higher and less variable than during the rest of the campaign $(0.91 \pm 0.03$ vs. $0.76 \pm 0.28)$. On the other hand, elevated sulfate mass fractions, particularly during late February, coincided with the highest $\kappa$ values observed for accumulation mode particles.
In Fig. 13 the effective hygroscopicity parameters derived from the $\mathrm{CCN}$ efficiency spectra measured at $S=0.10 \%\left(\kappa_{a}\right)$ are plotted against the organic mass fractions $\left(f_{\text {org }}\right)$ determined by integral and size-resolved AMS measurements, respectively. The close correlation between the integral composition data and the size-dependent hygroscopicity parameter $\left(R^{2}=0.81\right.$, Fig. $\left.13 \mathrm{a}\right)$ can be explained by the coincidence of the $\mathrm{CCN}$ activation diameter at $S=0.10 \%$ with the maximum of the aerosol mass size distribution $(\sim 200 \mathrm{~nm}$, Fig. 11a). The lower correlation coefficient obtained with the size-resolved AMS data $\left(R^{2}=0.66\right.$, Fig. $\left.13 \mathrm{~b}\right)$ is a result of the lower signal-to-noise of these data under the very low concentration conditions of this campaign.

At higher supersaturations corresponding to smaller CCN activation diameters $(S=0.19-0.82 \%, 50-130 \mathrm{~nm})$, neither the integral nor the size-resolved AMS data yielded close correlations between $\kappa_{a}$ and $f_{\text {org }}\left(R^{2}<0.5\right)$. With regard to the integral AMS data this is due to the size dependence of both $\kappa_{a}$ and $f_{\text {org }}$ (Figs. 3 and 11b), and with regard to the size-resolved AMS data it can be attributed to low signal-tonoise ratio.

Extrapolation of the fit lines in Fig. 13 to $f_{\text {org }}=1$ yields an effective hygroscopicity parameter $\kappa_{\text {org }} \approx 0.1$ for the organic fraction of the investigated aerosol particles (Fig. 13a: $0.09 \pm 0.01$; Fig. 13b: $0.11 \pm 0.01$; best fit values and standard errors of linear regression). Based on high-resolution AMS data and electron microscopic investigations (Chen et al., 2009; Sinha et al., 2009), the organic aerosol mass can largely be attributed to biogenic SOA production - especially for data points and periods with high organic mass fraction (such as the focus period) which dominate the right side and extrapolation of the linear correlation in Fig. 13a to $f_{\text {org }}=1$. Thus $\kappa_{\text {org }} \approx 0.1$ can be regarded as the effective hygroscopicity parameter characteristic for biogenic SOA from the tropical rainforest of Amazonia. To our knowledge, this is the first direct determination of the effective hygroscopicity of nearly pure biogenic SOA in the atmosphere. It is consistent with laboratory investigations of secondary organic aerosols (Petters and Kreidenweis, 2007; King et al., 2007; Prenni et al., 2007; Engelhart et al., 2008; Duplissy et al., 2008; AsaAwuku et al., 2009; Petters et al., 2009; Wex et al., 2009) and with recent field measurement results of Shantz et al. (2009), who reported $\kappa_{\text {org }} \approx 0.05-0.2$ for aerosols composed predominantly of organics from biogenic sources. Under the assumption that the surface tension of the aqueous droplet formed upon $\mathrm{CCN}$ activation equals the surface tension of pure water, the effective hygroscopicity parameter $\kappa_{\text {org }}$ can be interpreted as an "effective Raoult parameter", i.e. as an effective molar density of soluble molecules or ions in the dry organic material normalized by the molar density of water molecules in liquid water $\left(\rho_{w} / M_{w} \approx 55 \mathrm{~mol} \mathrm{~L}^{-1}\right.$; Mikhailov et al., 2009; Pöschl et al., 2009a): 

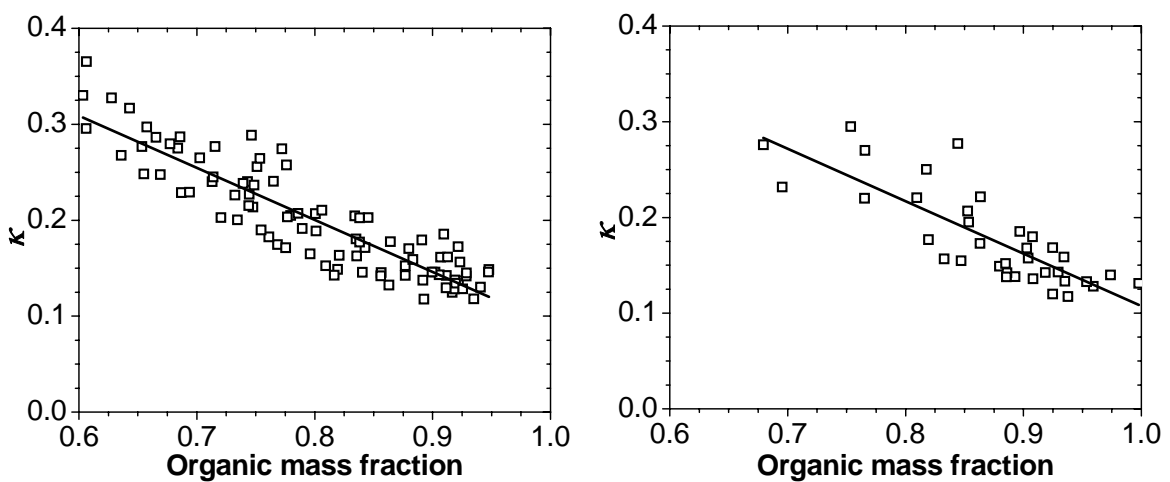

Fig. 13. Correlation between the effective hygroscopicity parameter of $\mathrm{CCN}$-active particles $\left(\kappa_{a}\right)$ observed at $S=0.1 \%$ and the organic mass fraction $\left(\int_{\text {org }}\right.$ ) determined by (a) integral and (b) size-resolved AMS measurements. Linear fit equations, correlation coefficients, and numbers of data points: (a) $y=0.634-0.543 x, R^{2}=0.81, n=97$; (b) $y=0.656-0.548 x, R^{2}=0.66, n=36$.

$\left.\kappa_{\text {org }} \approx i_{\text {org }} \rho_{\text {org }} / M_{\text {org }}\right) /\left(\rho_{w} / M_{w}\right)$

$\approx v_{\text {org }} \Phi_{\text {org }}\left(\rho_{\text {org }} / M_{\text {org }}\right) /\left(\rho_{w} / M_{w}\right)$

To calculate an effective average molecular mass of the organic compounds, $M_{\text {org }}$, we assume that the van't Hoff factor and the product of dissociation number and osmotic coefficient of the organic material, respectively, are close to unity $\left(i_{\mathrm{org}} \approx(v \Phi)_{\mathrm{org}} \approx 1\right)$ and that the density of the organic material is $\sim 1.4 \mathrm{~g} \mathrm{~cm}^{-3}$ (Cross et al., 2007; King et al., 2007). By inserting these values and $\kappa_{\text {org }} \approx 0.10$ into Eq. (2) we obtain an estimate of $M_{\mathrm{org}} \approx 250 \mathrm{~g} \mathrm{~mol}^{-1}$. This is of similar magnitude but somewhat higher than the value of $\sim 200 \mathrm{~g} \mathrm{~mol}^{-1}$ assumed by Ervens et al. (2007) and the values determined in recent studies of laboratory generated secondary organic aerosol ranging from $\sim 160 \mathrm{~g} \mathrm{~mol}^{-1}$ (AsaAwuku et al., 2009) to $\sim 180 \mathrm{~g} \mathrm{~mol}^{-1}$ (King et al., 2007; Engelhart et al., 2008). On the other hand, our estimate of $M_{\text {org }}$ for Amazonian aerosols is at the lower end of the range reported for the average molecular mass of watersoluble humic-like substances (HULIS) isolated from atmospheric aerosol samples, which is $215-345 \mathrm{~g} \mathrm{~mol}^{-1}$ according to Kiss et al. (2003) and 250-310 $\mathrm{g} \mathrm{mol}^{-1}$ according to Salma and Lang (2008), respectively. Note that Engelhart et al. (2008) and Asa-Awuku et al. (2009) had assumed higher densities $\left(1.5 \mathrm{~g} \mathrm{~cm}^{-3}\right)$, and Asa-Awuku et al. (2009) had assumed a lower surface tension $\left(0.065 \mathrm{~J} \mathrm{~m}^{-2}\right)$. If they had assumed the same density and surface tension as we did in our estimation $\left(1.4 \mathrm{~g} \mathrm{~cm}^{-3}, 0.072 \mathrm{~J} \mathrm{~m}^{-2}\right)$, they would have obtained values in the range of $\sim 200-240 \mathrm{~g} \mathrm{~cm}^{-3}$.

In analogy to Roberts et al. (2002), we think that surface tension effects are likely to be of limited importance for Amazonian aerosols, but we have no information about the actual surfactant activity of the organic fraction of the investigated aerosol particles. Recently Wex et al. (2009) suggested that the suface tension of aqueous SOA droplets is likely to be close to that of pure water $\left(>0.055 \mathrm{~J} \mathrm{~m}^{-2}\right)$. According to the relative sensitivities of surface tension and $\kappa$ when inter- preted as an effective Raoult parameter (Kreidenweis et al., 2009; Mikhailov et al., 2009; Pöschl et al., 2009a), a decrease of surface tension by $\sim 10 \%$ would be compensated by a decrease of the effective Raoult parameter by $\sim 30 \%$, and the latter would correspond to a $\sim 30 \%$ increase of the effective molar mass or a $\sim 30 \%$ decrease of the density of the organic material. In any case, the effective hygroscopicity parameter $\kappa_{\text {org }} \approx 0.10$ as defined above (Sect. 2.2 and references therein) accounts for both the Raoult effect related to molar mass and density of the solute, and for the Kelvin effect related to surfactant activity of the solute, regardless of their relative importance. The applicability of this approach is confirmed by the close linear correlation between $\kappa$ and $f_{\text {org }}$.

Extrapolation of the fit lines in Fig. 13 to $f_{\text {org }}=0$ yields $\kappa_{\text {inorg }} \approx 0.6$ for the inorganic fraction (Fig. 13a: $0.63 \pm 0.02$; Fig. 13b: $0.66 \pm 0.06$ ), which is characteristic for ammonium sulfate and related compounds (Petters and Kreidenweis, 2007; Rose et al., 2008a). In fact, the $\kappa$ values of most compounds typically contributing to the soluble inorganic fraction of continental aerosols are in the range of 0.6 to 0.9 (ammonium bisulfate, ammonium nitrate, sulfuric acid, etc.; Petters and Kreidenweis, 2007).

By definition, the mixing rule for the $\kappa$ values of different particle components refers to volume fractions, but mass fractions can be used for first-order approximations (Kreidenweis et al., 2008, 2009) assuming that the densities of individual components are similar to the overall particle density, which is reasonable for particles consisting mostly of organics $\left(\sim 1.3-1.4 \mathrm{~g} \mathrm{~cm}^{-3}\right)$ and sulfate $\left(\sim 1.8 \mathrm{~g} \mathrm{~cm}^{-3}\right.$; Cross et al., 2007; King et al., 2007; Chen et al., 2009). Thus we have used $\kappa_{\text {org }} \approx 0.1$ and $\kappa_{\text {inorg }} \approx \kappa_{\mathrm{AS}} \approx 0.6$ to predict effective hygroscopicity parameters from the organic and inorganic mass fractions determined by AMS ( $f_{\text {org }}$ and $\left.f_{\text {inorg }}=f_{\mathrm{SO}_{4}}+f_{\mathrm{NH}_{4}}+f_{\mathrm{NO}_{3}} \approx f_{\mathrm{SO}_{4}}\right)$ according to the following equation:

$\kappa_{p}=\kappa_{\text {org }} \times f_{\text {org }}+\kappa_{\text {inorg }} \times f_{\text {inorg }}=0.1 \times f_{\text {org }}+0.6 \times f_{\text {inorg }}$ 

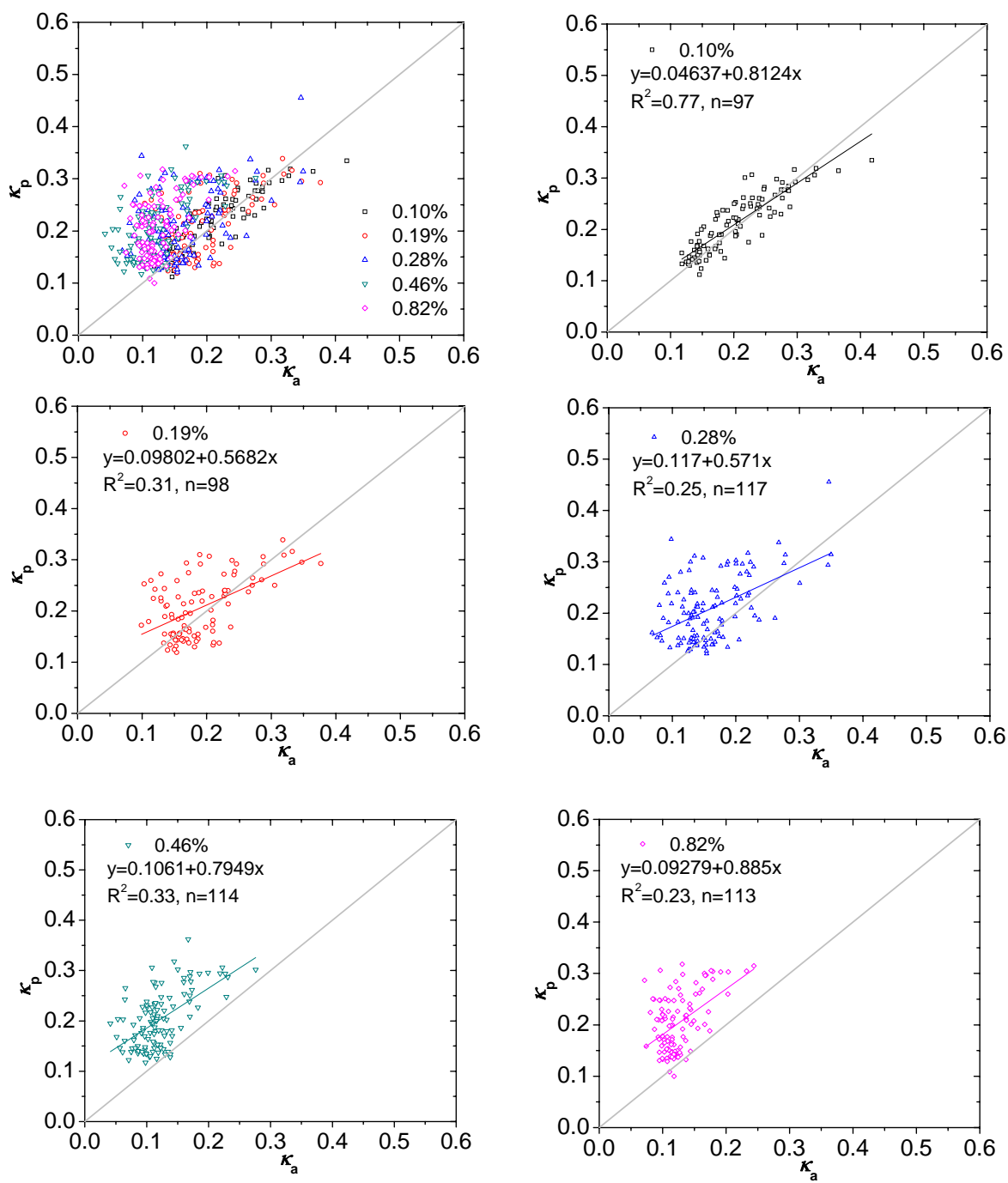

Fig. 14. Effective hygroscopicity parameters predicted from the organic and inorganic mass fractions determined by integral AMS measurements $\left(\kappa_{p}\right)$ plotted against the values obtained from CCN measurements $\left(\kappa_{a}\right)$ for all investigated supersaturations (a) and for individual supersaturations ((b)-(f), $S=0.10-0.82 \%)$. The colored lines are standard linear least-squares fits, and the diagonal grey lines indicate 1:1 ratio.

Note that this is consistent with the approach that King et al. (2009) have developed and successfully applied to describe the CCN properties of mixed SOA-sulfate particles in laboratory experiments. Moreover, Dusek et al. (2009a) recently found a similar correlation between AMS measurement-based organic and inorganic mass fractions and the effective hygroscopicity of aerosol particles in central Europe.

In Fig. 14 the $\kappa$ values predicted from the AMS measurement data $\left(\kappa_{p}\right)$ are plotted against the $\kappa$ values derived from the 3-parameter fits to the measured $\mathrm{CCN}$ efficiency spectra $\left(\kappa_{a}\right)$. As expected from the above findings, $\kappa_{p}$ exhibits a close correlation to $\kappa_{a}$ at $S=0.10 \%\left(R^{2}=0.77\right)$, no close correlation at $S=0.19-0.28 \%\left(R^{2}=0.2-0.3\right)$, and a pronounced positive bias at $S=0.46-0.82 \%\left(R^{2}=0.2-0.3\right)$. The mean rel- ative deviations and bias between $\kappa_{p}$ and $\kappa_{a}$ are summarized in Table 6. The strong positive bias of $\kappa_{p}$ at high $S$ (up to $+77 \%$ ) is due to the enhanced organic mass fraction in small particles and could be corrected on the basis of the average AMS size distribution data (Figs. 3 and 11b), but further processing of the AMS data would go beyond the scope of this study.

In spite of the positive bias and low correlation of predicted vs. measured $\kappa$ (Fig. 14, Table 6 ), the mean relative deviations between $\mathrm{CCN}$ number concentrations predicted on the basis of $\kappa_{p}$ and the measurement values of $N_{\mathrm{CCN}, S}$ were mostly less than $20 \%$ at $S=0.19-0.82 \%$ (Table 4 ), confirming the relatively low sensitivity of $N_{\mathrm{CCN}, S}$ against $\kappa$ as discussed above (Sect. 3.2). Although the correlation between $\kappa_{p}$ and $\kappa_{a}$ was much closer at $S=0.10 \%$ (Fig. 14, Table 6), 
Table 6. Characteristic deviations between hygroscopicity parameters determined by $\mathrm{CCN}$ measurements $\left(\kappa_{a}\right)$ and predicted on the basis of organic and inorganic mass fractions determined by integral AMS measurements $\left(\kappa_{p}\right)$ : arithmetic mean values of the relative bias $\left(\Delta_{\text {bias }} \kappa=\left(\kappa_{p}-\kappa_{a}\right) / \kappa_{a}\right)$ and of the total relative deviation $\left(\Delta_{\mathrm{dev}} \kappa=\left|\kappa_{p}-\kappa_{a}\right| / \kappa_{a}\right) . n$ is the number of data points.

\begin{tabular}{cccc}
\hline$S[\%]$ & bias [\%] & $\operatorname{dev}[\%]$ & $n$ \\
\hline 0.10 & +2.0 & 11.4 & 122 \\
0.19 & +6.9 & 25.1 & 128 \\
0.28 & +31.6 & 38.5 & 141 \\
0.46 & +77.0 & 77.3 & 144 \\
0.82 & +65.9 & 66.3 & 146 \\
All & +34.3 & 41.6 & 681 \\
\hline
\end{tabular}

the mean relative deviation between $N_{\mathrm{CCN}, S, p}$ and $N_{\mathrm{CCN}, S}$ at $S=0.10 \%(\sim 27 \%)$ was higher than at $S=0.19-0.82 \%(\sim 11-$ $23 \%$, Table 4). This confirms that the prediction of $N_{\mathrm{CCN}, S}$ is generally less robust at low $S$ (Rose et al., 2008b), which is due to the enhanced error sensitivity caused by the steep slope of the aerosol size distribution typically observed at the large activation diameters corresponding to low supersaturations (Ervens et al., 2007) and also to the stronger influence of externally mixed CCN-inactive particles at large $D$ and low $S$ (Figs. 2-3; Rose et al., 2008b, c).

Nevertheless, the AMS-based prediction of $N_{\mathrm{CCN}, S}$ at low $S$ worked much better here than in the study of Ervens et al. (2007), who predicted CCN number concentrations based on a combination of particle growth factors measured at subsaturated conditions and AMS data. At low $S(\sim 0.07 \%)$ they obtained CCN concentrations that were $\sim 2.4$ times higher than the measurement values. Note, however, that most likely this was primarily due to problems with the $\mathrm{CCN}$ measurement data related to the calibration of the applied CCNC, as hypothesized by Ervens et al. (2007) and confirmed by the results of Rose et al. (2008a). At high supersaturation, Ervens et al. (2007) achieved fair agreement between measured and predicted CCN concentrations. Other studies have also reported closure between $\mathrm{CCN}$ concentrations measured and calculated on the basis of chemical composition data from AMS measurements (e.g. Broekhuizen, et al., 2006; Dusek et al., 2006; Medina et al., 2007; Kuwata et al., 2008; Sorooshian et al., 2008; Wang et al., 2008; Shinozuka et al., 2009) and from filter or impactor sample analyses (e.g. Roberts et al., 2002; Bugiatioti et al., 2009). Moreover, Broekhuizen et al. (2006) and Medina et al. (2007) demonstrated that size-resolved chemical composition data lead to better agreement between measured and calculated $\mathrm{CCN}$ concentrations.

The results of our study confirm that integral AMS measurement data can be used for the prediction of CCN number concentrations from $\mathrm{CN}$ size distributions also at very low aerosol concentration levels and high organic mass fractions. Highly precise predictions, however, would require sizeresolved AMS measurement data of high precision, which are difficult to obtain at the concentration levels of pristine tropical rainforest air.

\section{Summary and conclusions}

\subsection{Intensive aerosol and $\mathrm{CCN}$ properties}

In this paper we presented the first size-resolved CCN measurements in Amazonia. The dry CCN activation diameters measured during AMAZE-08 at $S=0.10-0.82 \%$ were in the range of $40-240 \mathrm{~nm}$, corresponding to effective hygroscopicity parameters $\kappa$ in the range of $0.05-0.45$. The overall median value of $\kappa \approx 0.15$ is only half of the value typically observed for continental aerosols in other regions of the world, and Aitken mode particles ( $D \approx 50-90 \mathrm{~nm}, \kappa \approx 0.1)$ were on average less hygroscopic than accumulation mode particles ( $D \approx 100-200 \mathrm{~nm}, \kappa \approx 0.2$ ), which is in good agreement with the results of HTDMA measurements in earlier studies (Zhou et al., 2002; Vestin et al., 2007).

The hygroscopicity parameters derived from the CCN measurements are consistent with AMS measurement data showing that the organic mass fraction was on average as high as $\sim 90 \%$ in the Aitken mode $(D<100 \mathrm{~nm})$ and a little lower in the accumulation mode $(\sim 80 \%$ at $D \approx 200 \mathrm{~nm})$. The $\kappa$ values that were determined at low supersaturation, and are most characteristic for the accumulation mode, exhibited a close linear correlation with $f_{\text {org }}$. Extrapolation yielded effective average hygroscopicity parameters for the organic and inorganic particle components: $\kappa_{\text {org }} \approx 0.1$ is consistent with laboratory studies of secondary organic aerosol and indicates an effective average molecular mass of $\sim 230$ $250 \mathrm{~g} \mathrm{~mol}^{-1}$ for the organic compounds; $\kappa_{\text {inorg }} \approx 0.6$ is characteristic for ammonium sulfate and related compounds.

From these results we derived a simple parameterization that approximately describes both the size-dependence and the temporal variability of particle hygroscopicity as a function of AMS-based organic and inorganic mass fractions: $\kappa_{p}=\kappa_{\text {org }} \times f_{\text {org }}+\kappa_{\text {inorg }} \times f_{\text {inorg }}$. Predicted and measured $\kappa$ values were in fair agreement, and the mean relative deviation between $\mathrm{CCN}$ number concentrations predicted with a $\kappa$ Köhler model using $\kappa_{p}$ and measured CCN number concentrations was $\sim 20 \%$.

\subsection{Extensive aerosol and $\mathrm{CCN}$ properties}

The median $\mathrm{CCN}$ number concentrations were in the range of $N_{\mathrm{CCN}, 0.10} \approx 35 \mathrm{~cm}^{-3}$ to $N_{\mathrm{CCN}, 0.82} \approx 160 \mathrm{~cm}^{-3}$, and the median concentration of aerosol particles with $D>30 \mathrm{~nm}$ was $N_{\mathrm{CN}, 30} \approx 200 \mathrm{~cm}^{-3}$. The corresponding integral $\mathrm{CCN}$ efficiencies were in the range of $N_{\mathrm{CCN}, 0.10} / N_{\mathrm{CN}, 30} \approx 0.1$ to $N_{\mathrm{CCN}, 0.10} / N_{\mathrm{CN}, 30} \approx 0.8$, which is in good agreement with earlier studies (Roberts et al., 2001, 2002; Zhou et al., 2002; 
Andreae et al., 2004; Rissler et al., 2004, 2006; Vestin et al., 2007). Although the number concentrations and hygroscopicity parameters were much lower, the average integral $\mathrm{CCN}$ efficiencies observed in pristine rainforest air were similar to those reported by Rose et al. (2008) for highly polluted megacity air and to the global average values reported by Andreae (2009).

Test calculations with different model approaches also confirmed the suitability of $\kappa$-Köhler models for the approximation/prediction of CCN number concentrations (Rose et al., 2008b). With hygroscopicity parameters derived from $\mathrm{CCN}$ or AMS measurement data, the deviation between model and measurement values of $N_{\mathrm{CCN}, S}$ was generally less than $10-20 \%$. As expected, the calculation of $N_{\mathrm{CCN}, S}$ with an approximate global average value of $\kappa \approx 0.3$ led to overpredictions, but the relative deviations exceeded $\sim 50 \%$ only at low water vapor supersaturation $(0.1 \%)$ and particle number concentrations $\left(\leq 100 \mathrm{~cm}^{-3}\right)$. Model calculations assuming a constant aerosol size distribution led to higher average deviations at all investigated levels of supersaturation: $\sim 60 \%$ using the campaign average distribution and $\sim 1600 \%$ using a generic remote continental distribution.

\subsection{General aspects}

The similar integral $\mathrm{CCN}$ efficiencies observed in pristine tropical rainforest and in highly polluted megacities, the relatively small errors in predicting $N_{\mathrm{CCN}, S}$ with an approximate global average value $\kappa \approx 0.3$, and the much larger errors in predicting $N_{\mathrm{CCN}, S}$ under the assumption of a constant size distribution (factor $\sim 4-27$ ) confirm earlier studies suggesting that aerosol particle number and size are the major predictors for the variability of the $\mathrm{CCN}$ concentration in continental boundary layer air, followed by particle composition and hygroscopicity as relatively minor modulators (Feingold et al., 2001; Feingold, 2003; Dusek et al., 2006; Ervens et al., 2007; Andreae and Rosenfeld, 2008; Andreae, 2009; Rose et al., 2008b; Anderson et al., 2009; Feingold and Siebert, 2009; Kreidenweis et al., 2009; Pöschl et al., 2009a; Reutter et al., 2009). At low $S$, however, $N_{\mathrm{CCN}, S}$ remains difficult to predict with high accuracy. All tested model approaches yielded mean relative deviations larger than $10 \%$ at $S=0.1 \%$, and model studies show that the sensitivity of cloud droplet formation to aerosol particle properties is highest at low $S$ (updraft limited regime of CCN activation; Reutter et al., 2009 and references therein).

Thus, we suggest that future $\mathrm{CCN}$ measurements should be focused on low water vapor supersaturation, where great care should be taken with regard to instrument calibration (Rose et al., 2008a). In the meantime, the information and parameterizations presented in this and related papers (Table 2) should enable efficient description of the CCN properties of pristine Amazonian rainforest aerosols in detailed cloud process models as well as in large-scale atmospheric and climate models.

\section{Appendix A}

\section{Notation (frequently used symbols).}

\begin{tabular}{|c|c|}
\hline Symbol & Quantity, Unit \\
\hline$D$ & mobility equivalent particle diameter, $\mathrm{nm}$ \\
\hline$D_{a}$ & $\begin{array}{l}\text { midpoint activation diameter determined by } \\
\text { 3-parameter } \mathrm{CDF} \text { fit, } \mathrm{nm}\end{array}$ \\
\hline$D_{t}$ & $\begin{array}{l}\text { midpoint activation diameter determined by } \\
\text { 2-parameter CDF fit, } \mathrm{nm}\end{array}$ \\
\hline$M A F_{f}$ & $\begin{array}{l}\text { maximum activated fraction determined by } \\
\text { 3-parameter CDF fit }\end{array}$ \\
\hline$N_{\mathrm{CCN}, S}$ & $\begin{array}{l}\text { number concentration of cloud condensation } \\
\text { nuclei }(\mathrm{CCN}) \text { at supersaturation } S, \mathrm{~cm}^{-3}\end{array}$ \\
\hline$N_{\mathrm{CCN}, S, p}$ & $\begin{array}{l}\text { predicted CCN number concentration at } \\
\text { supersaturation } S, \mathrm{~cm}^{-3}\end{array}$ \\
\hline$N_{\mathrm{CCN}, S} / N_{\mathrm{CN}, 30}$ & $\begin{array}{l}\text { integral CCN efficiency (relative to } \\
\left.N_{\mathrm{CN}, 30}\right), \mathrm{cm}^{-3}\end{array}$ \\
\hline$N_{\mathrm{CN}, 30}$ & $\begin{array}{l}\text { number concentration of aerosol particles } \\
(\mathrm{CN}) \text { with } D>30 \mathrm{~nm}, \mathrm{~cm}^{-3}\end{array}$ \\
\hline$S$ & water vapor supersaturation, $\%$ \\
\hline$f_{\text {org }}$ & organic mass fraction determined by AMS \\
\hline$f_{\text {inorg }}$ & $\begin{array}{l}\text { inorganic mass fraction determined by } \\
\text { AMS (sulfate and other ions) }\end{array}$ \\
\hline$\kappa$ & effective hygroscopicity parameter \\
\hline$\kappa_{a}$ & $\begin{array}{l}\text { effective hygroscopicity parameter } \\
\text { determined by } 3 \text {-parameter CDF fit } \\
\text { (characteristic for CCN-active particles) }\end{array}$ \\
\hline$\kappa_{p}$ & $\begin{array}{l}\text { effective hygroscopicity parameter } \\
\text { predicted from AMS-based } \\
\text { parameterization (organic and } \\
\text { inorganic mass fractions) }\end{array}$ \\
\hline$\kappa_{t}$ & $\begin{array}{l}\text { effective hygroscopicity parameter } \\
\text { determined by 2-parameter CDF fit } \\
\text { (proxy for overall population of } \\
\text { aerosol particles) }\end{array}$ \\
\hline$\kappa_{t, \text { avg }}$ & $\begin{array}{l}\text { effective hygroscopicity parameter } \\
\text { determined by averaging over } \\
\text { externally mixed particle groups }\end{array}$ \\
\hline
\end{tabular}

Acknowledgements. This study was supported by the Max Planck Society (MPG), the European integrated project on aerosol cloud climate and air quality interactions (No. 036833-2, EUCAARI), and the Humboldt Foundation (STM Research Fellowship). STM and JLJ acknowledge support received from the US National Science Foundation (ATM-0723582). STM also acknowledges support of the Office of Science (BES), US Department of Energy, Grant No. DE-FG02-08ER64529. DKF and JLJ were supported by a NOAA Global Change Postdoctoral Fellowship and NSF grant ATM-0449815. QC acknowledges a NASA Earth and Space Science Fellowship. DKF acknowledges a NOAA Global Change fellowship. Thanks to all AMAZE-08 team members - especially to R. Garland, T. Pauliquevis, F. Morais, P. H. Oliveira, J. Kayse, J. Schneider, S. Zorn, M. Petters and E. Mikhailov - for help, collaboration and exchange during and after the campaign; to A. Wiedensohler and colleagues from IfT Leipzig for preparing the inlet and drying system; to G. Frank, T. Hussein (University 
of Helsinki), H. Su and J. Mayer for support in the data analysis; and to N. Jürgens, D. Pickersgill, J. Schöngart, F. Wittmann, A. Bracho-Nunez, N. Knothe, M. T. Piedade, J. Kesselmeier and the INPA-MPI team for support in the preparation and completion of the campaign. We also thank INPA and the LBA Office in Manaus for logistical support.

The service charges for this open access publication

have been covered by the Max Planck Society.

Edited by: H. Coe

\section{References}

Anderson, T., Ackerman, A., Hartmann, D., Isaac, G., Kinne, S., Masunaga, H., Norris, J., Pöschl, U., Schmidt, S., Slingo, A. A., and Takayabu, Y.: Temporal and Spatial Variability of Clouds and Related Aerosols, in: Clouds in the Perturbed Climate System, edited by: Heintzenberg, J. and Charlson, R. J., MIT Press, Cambridge, ISBN 978-0-262-012874, 127-148, 2009.

Andreae, M. O.: Aerosols before pollution, Science, 315(5808), 50-51, 2007.

Andreae, M. O.: Correlation between cloud condensation nuclei concentration and aerosol optical thickness in remote and polluted regions, Atmos. Chem. Phys., 9, 543-556, 2009, http://www.atmos-chem-phys.net/9/543/2009/.

Andreae, M. O. and Rosenfeld, D.: Aerosol-cloud-precipitation interactions. Part 1, The nature and sources of cloud-active aerosols, Earth-Sci. Rev., 89, 13-41, 2008.

Andreae, M. O., Rosenfeld, D., Artaxo, P., Costa, A. A., Frank, G. P., Longo, K. M., and Silva-Dias, M. A. F.: Smoking rain clouds over the Amazon, Science, 303(5662), 1337-1342, 2004.

Artaxo, P., Fernandes, E. T., Martins, J. V., Yamasoe, M. A., Hobbs, P. V., Maenhaut, W., Longo, K. M., and Castanho, A.: Largescale aerosol source apportionment in Amazonia, J. Geophys. Res.-Atmos., 103(D24), 31837-31847, 1998.

Artaxo, P., Maenhaut, W., Storms, H., and Van Grieken, R.: Aerosol Characteristics and Sources for the Amazon Basin During the Wet Season, J. Geophys. Res.-Atmos., 95(D10), 16971-16985, 1990.

Artaxo, P., Martins, J. V., Yamasoe, M. A., Procopio, A. S., Pauliquevis, T. M., Andreae, M. O., Guyon, P., Gatti, L. V., and Leal, A. M. C.: Physical and chemical properties of aerosols in the wet and dry seasons in Rondonia, Amazonia, J. Geophys. Res.-Atmos., 107(D20), 8081, doi:10.1029/2001JD000666, 2002.

Asa-Awuku, A., Engelhart, G. J., Lee, B. H., Pandis, S. N., and Nenes, A.: Relating CCN activity, volatility, and droplet growth kinetics of $\beta$-caryophyllene secondary organic aerosol, Atmos. Chem. Phys., 9, 795-812, 2009, http://www.atmos-chem-phys.net/9/795/2009/.

Broekhuizen, K., Chang, R.Y.-W., Leaitch, W. R., Li, S.-M., and Abbatt, J. P. D.: Closure between measured and modeled cloud condensation nuclei (CCN) using size-resolved aerosol compositions in downtown Toronto, Atmos. Chem. Phys., 6, 2513-2524, 2006,

http://www.atmos-chem-phys.net/6/2513/2006/.

Bougiatioti, A., Fountoukis, C., Kalivitis, N., Pandis, S. N., Nenes, A., and Mihalopoulos, N.: Cloud condensation nuclei measurements in the eastern Mediterranean marine boundary layer: $\mathrm{CCN}$ closure and droplet growth kinetics, Atmos. Chem. Phys. Discuss., 9, 10303-10336, 2009,

http://www.atmos-chem-phys-discuss.net/9/10303/2009/.

Canagaratna, M. R., Jayne, J. T., Jimenez, J. L., Allan, J. D., Alfarra, M. R., Zhang, Q., Onasch, T. B., Drewnick, F., Coe, H., Middlebrook, A., Delia, A., Williams, L. R., Trimborn, A. M., Northway, M. J., DeCarlo, P. F., Kolb, C. E., Davidovits, P., and Worsnop, D. R.: Chemical and microphysical characterization of ambient aerosols with the aerodyne aerosol mass spectrometer, Mass Spectrom. Rev., 26(2), 185-222, 2007.

Chen, Q., Farmer, D., Allan, J., Borrmann, S., Coe, H., Robinson, N., Schneider, J., Zom, S., Artaxo, P., Jimenez, J. L., and Martin, S. T.: Characterization of organic aerosol with a high-resolution time-of-flight aerosol mass spectrometer during the Amazonian Aerosol Characterization Experiment (AMAZE-08), American Association for Aerosol Research, 2008.

Chen, Q., Farmer, D. K., Schneider, J., Zorn, S. R., Heald, C. L., Karl, T. G., Guenther, A., Allan, J. D., Robinson, N., Coe, H., Kimmel, J. R., Pauliquevis, T., Borrmann, S., Pöschl, U., Andreae, M. O., Artaxo, P., Jimenez, J. L., and Martin, S. T.: Mass spectral characterization of submicron biogenic organic particles in the Amazon basin, Geophys. Res. Lett., doi:10.1029/2009GL039880, in press, 2009.

Cross, E. S., Slowik, J. G., Davidovits, P., Allan, J. D., Worsnop, D. R., Jayne, J. T., Lewis, D. K., Canagaratna, M., and Onasch, T. B.: Laboratory and ambient particle density determinations using light scattering in conjunction with aerosol mass spectrometry, Aerosol Sci. Tech., 41, 343-359, 2007.

DeCarlo, P. F., Kimmel, J. R., Trimborn, A., Northway, M. J., Jayne, J. T., Aiken, A. C., Gonin, M., Fuhrer, K., Horvath, T., Docherty, K. S., Worsnop, D. R., and Jimenez, J. L.: Field-deployable, high-resolution, time-of-flight aerosol mass spectrometer, Anal. Chem., 78(24), 8281-8289, 2006.

DeCarlo, P. F., Slowik, J. G., Worsnop, D. R., Davidovits, P., and Jimenez, J. L.: Particle morphology and density characterization by combined mobility and aerodynamic diameter measurements, Part 1: Theory, Aerosol Sci. Tech., 38(12), 1185-1205, 2004.

Duplissy, J., Gysel, M., Alfarra, M. R., Dommen, J., Metzger, A., Prevot, A. S. H., Weingartner, E., Laaksonen, A., Raatikainen, T., Good, N., Turner, S. F., McFiggans, G., and Baltensperger, U.: Cloud forming potential of secondary organic aerosol under near atmospheric conditions, Geophys. Res. Lett., 35(3), L03818, doi:10.1029/2007GL031075, 2008.

Dusek, U., Frank, G. P., Curtius, J., Drewnick, F., Schneider, J., Kürten, A., Rose, D., Andreae, M. O., Borrmann, S., and Pöschl, U.: Enhanced organic mass fraction and decreased hygroscopicity of cloud condensation nuclei $(\mathrm{CCN})$ during new particle formation events, Geophys. Res. Lett., submitted, 2009a.

Dusek, U., Hessberg, C., Pöschl, U., et al.: CCN activity of laboratory generated SOA particles, in preparation, 2009b.

Dusek, U., Frank, G. P., Hildebrandt, L., Curtius, J., Schneider, J., Walter, S., Chand, D., Drewnick, F., Hings, S., Jung, D., Borrmann, S., and Andreae, M. O.: Size matters more than chemistry for cloud nucleating ability of aerosol particles, Science, 312, 1375-1378, 2006.

Engelhart, G. J., Asa-Awuku, A., Nenes, A., and Pandis, S. N.: $\mathrm{CCN}$ activity and droplet growth kinetics of fresh and aged monoterpene secondary organic aerosol, Atmos. Chem. Phys., 8, 3937-3949, 2008, 
http://www.atmos-chem-phys.net/8/3937/2008/.

Ervens, B., Cubison, M., Andrews, E., Feingold, G., Ogren, J. A., Jimenez, J. L., DeCarlo, P., and Nenes, A.: Prediction of cloud condensation nucleus number concentration using measurements of aerosol size distributions and composition and light scattering enhancement due to humidity, J. Geophys. Res.-Atmos., 112(D10), D10S32, doi:10.1029/2006JD007426, 2007.

Feingold, G. and Siebert, H.: Cloud-aerosol interactions from the micro to the cloud scale, in: Clouds in the Perturbed Climate System, edited by: Heintzenberg, J. and Charlson, R. J., MIT Press, Cambridge, ISBN 978-0-262-012874, 319-338, 2009.

Feingold, G.: Modeling of the first indirect effect: Analysis of measurement requirements, Geophys. Res. Lett., 30(19), 1997, doi:10.1029/2003GL017967, , 2003.

Feingold, G., Remer, L. A., Ramaprasad, J., and Kaufman, Y. J.: Analysis of smoke impact on clouds in Brazilian biomass burning regions: An extension of Twomey's approach, J. Geophys. Res.-Atmos., 106(D19), 22907-22922, 2001

Frank, G. P., Dusek, U., and Andreae, M. O.: Technical note: A method for measuring size-resolved $\mathrm{CCN}$ in the atmosphere, Atmos. Chem. Phys. Discuss., 6, 4879-4895, 2006, http://www.atmos-chem-phys-discuss.net/6/4879/2006/.

Freud, E., Rosenfeld, D., Andreae, M. O., Costa, A. A., and Artaxo, P.: Robust relations between $\mathrm{CCN}$ and the vertical evolution of cloud drop size distribution in deep convective clouds, Atmos. Chem. Phys., 8, 1661-1675, 2008, http://www.atmos-chem-phys.net/8/1661/2008/.

Hussein, T., Dal Maso, M., Petaja, T., Koponen, I. K., Paatero, P., Aalto, P. P., Hameri, K., and Kulmala, M.: Evaluation of an automatic algorithm for fitting the particle number size distributions, Boreal Environ. Res., 10, 337-355, 2005.

IAPSAG, WMO/IUGG International Aerosol Precipitation Science Assessment Group (IAPSAG) Report: Aerosol Pollution Impact on Precipitation: A Scientific Review, Geneva, World Meteorological Organization, 482, 2007.

IPCC, Solomon, S., Qin, D., Manning, M., Chen, Z., Marquis, M., Averyt, K., Tignor, M., and Miller, H. L.: Climate Change 2007: The Physical Science Basis, Contribution of Working Group I to the Fourth Assessment Report of the Intergovernmental Panel on Climate Change, Cambridge and New York, Cambridge University Press, 996, 2007.

Jaenicke, R.: Aerosol cloud climate interaction, Tropospheric aerosols, edited by: Hobbs, P. V., Academic Press, San Diego, CA, pp. 1-31, 1993.

King, S. M., Rosenoern, T., Shilling, J. E., Chen, Q., and Martin, S. T.: Increased cloud activation potential of secondary organic aerosol for atmospheric mass loadings, Atmos. Chem. Phys., 9, 2959-2971, 2009,

http://www.atmos-chem-phys.net/9/2959/2009/.

King, S. M., Rosenoern, T., Shilling, J. E., Chen, Q., and Martin, S. T.: Cloud condensation nucleus activity of secondary organic aerosol particles mixed with sulfate, Geophys. Res. Lett., 34(24), L24806, doi:10.1029/2007GL030390, 2007.

Kinne, S.: Climatologies of Cloud-related Aerosols: Part 1: Particle number and size, in: Clouds in the Perturbed Climate System, edited by: Heintzenberg, J. and Charlson, R. J., MIT Press, Cambridge, ISBN 978-0-262-012874, 37-57, 2009.

Kiss, G., Tombacz, E., Varga, B., Alsberg, T., and Persson, L.: Estimation of the average molecular weight of humic-like substances isolated from fine atmospheric aerosol, Atmos. Environ., 37(27), 3783-3794, 2003.

Kostenidou, E., Pathak, R. K., and Pandis, S. N.: An algorithm for the calculation of secondary organic aerosol density combining AMS and SMPS data, Aerosol Sci. Tech., 41(11), 1002-1010, 2007.

Kreidenweis, S. M., Petters, M. D., and DeMott, P. J.: Singleparameter estimates of aerosol water content, Environ. Res. Lett., 3(3), 035002, doi:10.1088/1748-9326/3/3/035002, 2008.

Kreidenweis, S. M., Petters, M. D., and Chuang, P. Y.: Cloud particle precursors, in: Clouds in the Perturbed Climate System, edited by: Heintzenberg, J. and Charlson, R. J., MIT Press, Cambridge, ISBN 978-0-262-012874, 291-318, 2009.

Kuwata, M., Kondo, Y., Miyazaki, Y., Komazaki, Y., Kim, J. H., Yum, S. S., Tanimoto, H., and Matsueda, H.: Cloud condensation nuclei activity at Jeju Island, Korea in spring 2005, Atmos. Chem. Phys., 8, 2933-2948, 2008, http://www.atmos-chem-phys.net/8/2933/2008/.

Lance, S., Medina, J., Smith, J. N., and Nenes, A.: Mapping the Operation of the DMT Continuous Flow CCN Counter, Aerosol Sci. Tech., 40(4), 242-254, 2006.

Liu, P. S. K., Deng, R., Smith, K. A., Williams, L. R., Jayne, J. T., Canagaratna, M. R., Moore, K., Onasch, T. B., Worsnop, D. R., and Deshler, T.: Transmission efficiency of an aerodynamic focusing lens system: Comparison of model calculations and laboratory measurements for the Aerodyne Aerosol Mass Spectrometer, Aerosol Sci. Tech., 41(8), 721-733, 2007.

Martin, S. T., Andreae, M. O., Artaxo, P., Baumgardner, D., Chen, Q., Goldstein, A. H., Guenther, A., Heald, C. L., Mayol-Bracero, O. L., McMurry, P. H., Pauliquevis, T., Pöschl, U., Prather, K. A., Roberts, G. C., Saleska, S. R., Silva-Dias, M. A., Spracklen, D. V., Swietlicki, E., and Trebs, I.: Sources and properties of Amazonian aerosols particles, Rev. Geophys., in press, 2009a.

Martin, S. T., Artaxo, P., Andreae, M. O., et al.: Amazonian Aerosol Characterization Experiment 2008 (AMAZE-08), Atmos. Chem. Phys., in preparation, 2009b.

Martins, J. A., Goncalves, F. L. T., Morales, C. A., Fisch, G. F., Pinheiro, F. G. M., Leal, J. B. V., Oliveira, C. J., Silva, E. M., Oliveira, J. C. P., Costa, A. A., and Dias, M.: Cloud condensation nuclei from biomass burning during the Amazonian dry-towet transition season, Meteorol. Atmos. Phys., 104(1-2), 83-93, 2009.

McFiggans, G., Artaxo, P., Baltensperger, U., Coe, H., Facchini, M. C., Feingold, G., Fuzzi, S., Gysel, M., Laaksonen, A., Lohmann, U., Mentel, T. F., Murphy, D. M., O’Dowd, C. D., Snider, J. R., and Weingartner, E.: The effect of physical and chemical aerosol properties on warm cloud droplet activation, Atmos. Chem. Phys., 6, 2593-2649, 2006,

http://www.atmos-chem-phys.net/6/2593/2006/.

Medina, J., Nenes, A., Sotiropoulou, R.-E. P., Cottrell, L. D., Ziemba, L. D., Beckman, P. J., and Griffin, R. J.: Cloud condensation nuclei closure during the International Consortium for Atmospheric Research on Transport and Transformation 2004 campaign: Effects of size-resolved composition, J. Geophys. Res., 112, D10S31, doi:10.1029/2006JD007588, 2007.

Mikhailov, E., Vlasenko, S., Martin, S. T., Koop, T., and Pöschl, U.: Amorphous and crystalline aerosol particles interacting with water vapor - Part 1: Microstructure, phase transitions, hygroscopic growth and kinetic limitations, Atmos. Chem. Phys. Discuss., 9, 
7333-7412, 2009,

http://www.atmos-chem-phys-discuss.net/9/7333/2009/.

Petters, M. D., Wex, H., Carrico, C. M., Hallbauer, E., Massling, A., McMeeking, G. R., Poulain, L., Wu, Z., Kreidenweis, S. M., and Stratmann, F.: Towards closing the gap between hygroscopic growth and activation for secondary organic aerosol - Part 2: Theoretical approaches, Atmos. Chem. Phys., 9, 39994009, 2009, http://www.atmos-chem-phys.net/9/3999/2009/.

Petters, M. D. and Kreidenweis, S. M.: A single parameter representation of hygroscopic growth and cloud condensation nucleus activity, Atmos. Chem. Phys., 7, 1961-1971, 2007, http://www.atmos-chem-phys.net/7/1961/2007/.

Pöschl, U., Rose, D., and Andreae, M. O.: Climatologies of Cloudrelated Aerosols - Part 2: Particle Hygroscopicity and Cloud Condensation Nuclei Activity, in: Clouds in the Perturbed Climate System, edited by: Heintzenberg, J. and Charlson, R. J., MIT Press, Cambridge, ISBN 978-0-262-012874, 58-72, 2009a.

Pöschl, U., Andreae, M. O., Sinha, B. et al.: Amazonian aerosols: bioparticles and organics with a grain of salt, in preparation, 2009b.

Prenni, A. J., Petters, M. D., Kreidenweis, S. M., DeMott, P. J., and Ziemann, P. J.: Cloud droplet activation of secondary organic aerosol, J. Geophys. Res.-Atmos., 112(D10), D10223, doi:10.1029/2006JD007963, 2007.

Pruppacher, H. R. and Klett, J. D.: Microphysics of clouds and precipitation, Dordrecht, Kluwer Academic Publishers, 1997.

Reutter, P., Trentmann, J., Su, H., Simmel, M., Rose, D., Gunthe, S. S., Wernli, H., Andreae, M. O., and Pöschl, U.: Aerosol- and updraft-limited regimes of cloud droplet formation: influence of particle number, size and hygroscopicity on the activation of cloud condensation nuclei (CCN), Atmos. Chem. Phys., 9, 70677080, 2009, http://www.atmos-chem-phys.net/9/7067/2009/.

Rissler, J., Swietlicki, E., Zhou, J., Roberts, G., Andreae, M. O., Gatti, L. V., and Artaxo, P.: Physical properties of the submicrometer aerosol over the Amazon rain forest during the wetto-dry season transition - comparison of modeled and measured CCN concentrations, Atmos. Chem. Phys., 4, 2119-2143, 2004, http://www.atmos-chem-phys.net/4/2119/2004/.

Rissler, J., Vestin, A., Swietlicki, E., Fisch, G., Zhou, J., Artaxo, P., and Andreae, M. O.: Size distribution and hygroscopic properties of aerosol particles from dry-season biomass burning in Amazonia, Atmos. Chem. Phys., 6, 471-491, 2006, http://www.atmos-chem-phys.net/6/471/2006/.

Roberts, G. C., Andreae, M. O., Zhou, J., and Artaxo, P.: Cloud condensation nuclei in the Amazon Basin: "marine" conditions over a continent?, Geophysical Research Letters, 28(14), 28072810, 2001.

Roberts, G. C., Artaxo, P., Jingchuan, Z., Swietlicki, E., and Andreae, M. O.: Sensitivity of CCN spectra on chemical and physical properties of aerosol: a case study from the Amazon Basin, J. Geophys. Res., 107(D20), LBA37-1-18, 2002.

Roberts, G. C. and Nenes, A.: A Continuous-Flow Streamwise Thermal-Gradient CCN Chamber for Atmospheric Measurements, Aerosol Sci. Tech., 39(3), 206-221, 2005.

Roberts, G. C., Nenes, A., Seinfeld, J. H., and Andreae, M. O.: Impact of biomass burning on cloud properties in the Amazon Basin, J. Geophys. Res.-Atmos., 108(D2), doi:10.1029/2001JD000985, 2003.
Roberts, G. C., Ramana, M. V., Corrigan, C., Kim, D., and Ramanathan, V.: Simultaneous observations of aerosol-cloudalbedo interactions with three stacked unmanned aerial vehicles, P. Natl. Acad. Sci. USA, 105(21), 7370-7375, 2008.

Roberts, G.: Interactive comment on "Cloud condensation nuclei in pristine tropical rainforest air of Amazonia: size resolved measurements and modeling of atmospheric aerosol composition and CCN activity", Atmos. Chem. Phys. Discuss., 9, 1384-1387, 2009, http://www.atmos-chem-phys-discuss.net/9/1384/2009/.

Roldin, P., Nilsson, E., Swietlicki, E., Massling, A., and Zhou, J.: Lund SMPS User's manual, EUCAARI Brazil version, 2008.

Rose, D., Gunthe, S. S., Mikhailov, E., Frank, G. P., Dusek, U., Andreae, M. O., and Pöschl, U.: Calibration and measurement uncertainties of a continuous-flow cloud condensation nuclei counter (DMT-CCNC): CCN activation of ammonium sulfate and sodium chloride aerosol particles in theory and experiment, Atmos. Chem. Phys., 8, 1153-1179, 2008, http://www.atmos-chem-phys.net/8/1153/2008/.

Rose, D., Nowak, A., Achtert, P., Wiedensohler, A., Hu, M., Shao, M., Zhang, Y., Andreae, M. O., and Pöschl, U.: Cloud condensation nuclei in polluted air and biomass burning smoke near the mega-city Guangzhou, China - Part 1: Size-resolved measurements and implications for the modeling of aerosol particle hygroscopicity and CCN activity, Atmos. Chem. Phys. Discuss., 8, 17343-17392, 2008,

http://www.atmos-chem-phys-discuss.net/8/17343/2008/.

Rose, D., Garland, R. M., Yang, H., Berghof, M., Wehner, B., Wiedensohler, A., Takegawa, N., Kondo, Y., Andreae, M. O. and Pöschl, U.: Cloud condensation nuclei in polluted air and biomass burning smoke near the mega-city Guangzhou, China - Part 2: CCN composition and diurnal cycles, Atmos. Chem. Phys., in preparation, 2009.

Rosenfeld, D., Lohmann, U., Raga, G. B., O’Dowd, C. D., Kulmala, M., Fuzzi, S., Reissell, A., and Andreae, M. O.: Flood or drought: How do aerosols affect precipitation?, Science, 321(5894), 1309-1313, 2008.

Salma, I. and Láng, G. G.: How many carboxyl groups does an average molecule of humic-like substances contain?, Atmos. Chem. Phys. Discuss., 8, 10005-10020, 2008,

http://www.atmos-chem-phys-discuss.net/8/10005/2008/.

Seinfeld, J. H. and Pandis, S. N.: Atmospheric chemistry and physics, from air pollution to climate change, John Wiley and Sons, 2006.

Sinha, B., Huth, J., Hoppe, P., et al.: Composition and mixing state of wet season tropical rain forest aerosol: A single particle study combining optical microscopy, SEM-EDX, NanoSIMS and AFM, in preparation, 2009.

Shantz, N. C., Chang, R. Y.-W., Slowik, J. G., Abbatt, J. P. D., and Leaitch, W. R.: Slower CCN growth kinetics of anthropogenic aerosol compared to biogenic aerosol observed at a rural site, Atmos. Chem. Phys. Discuss., 9, 13775-13799, 2009, http://www.atmos-chem-phys-discuss.net/9/13775/2009/.

Shinozuka, Y., Clarke, A. D., DeCarlo, P. F., Jimenez, J. L., Dunlea, E. J., Roberts, G. C., Tomlinson, J. M., Collins, D. R., Howell, S. G., Kapustin, V. N., McNaughton, C. S., and Zhou, J.: Aerosol optical properties relevant to regional remote sensing of $\mathrm{CCN}$ activity and links to their organic mass fraction: airborne observations over Central Mexico and the US West Coast during MILAGRO/INTEX-B, Atmos. Chem. Phys., 9, 6727-6742, 
2009, http://www.atmos-chem-phys.net/9/6727/2009/.

Sorooshian, A., Murphy, S. M., Hersey, S., Gates, H., Padro, L. T., Nenes, A., Brechtel, F. J., Jonsson, H., Flagan, R. C., and Seinfeld, J. H.: Comprehensive airborne characterization of aerosol from a major bovine source, Atmos. Chem. Phys., 8, 5489-5520, 2008, http://www.atmos-chem-phys.net/8/5489/2008/.

Talbot, R. W., Andreae, M. O., Berresheim, H., Artaxo, P., Garstang, M., Harriss, R. C., Beecher, K. M., and Li, S. M.: Aerosol Chemistry During the Wet Season in Central Amazonia - the Influence of Long-Range Transport, J. Geophys. Res.Atmos., 95(D10), 16955-16969, 1990.

Tsigaridis, K., Krol, M., Dentener, F. J., Balkanski, Y., Lathière, J., Metzger, S., Hauglustaine, D. A., and Kanakidou, M.: Change in global aerosol composition since preindustrial times, Atmos. Chem. Phys., 6, 5143-5162, 2006,

http://www.atmos-chem-phys.net/6/5143/2006/.

Vestin, A., Rissler, J., Swietlicki, E., Frank, G. P., and Andreae, M. O.: Cloud-nucleating properties of the Amazonian biomass burning aerosol: Cloud condensation nuclei measurements and modeling, J. Geophys.1 Res.-Atmos., 112(D14), D14201, doi:10.1029/2006JD008104, 2007.

Wang, J., Lee, Y.-N., Daum, P. H., Jayne, J., and Alexander, M. L.: Effects of aerosol organics on cloud condensation nucleus (CCN) concentration and first indirect aerosol effect, Atmos. Chem. Phys., 8, 6325-6339, 2008,

http://www.atmos-chem-phys.net/8/6325/2008/.
Wex, H., Petters, M. D., Carrico, C. M., Hallbauer, E., Massling, A., McMeeking, G. R., Poulain, L., Wu, Z., Kreidenweis, S. M., and Stratmann, F.: Towards closing the gap between hygroscopic growth and activation for secondary organic aerosol: Part 1 - Evidence from measurements, Atmos. Chem. Phys., 9, 3987-3997, 2009, http://www.atmos-chem-phys.net/9/3987/2009/.

Wex, H., Hennig, T., Salma, I., Ocskay, R., Kiselev, A., Henning, S., Massling, A., Wiedensohler, A., and Stratmann, F.: Hygroscopic growth and measured and modeled critical supersaturations of an atmospheric HULIS sample, Geophys. Res. Lett., 34(2), L02818, doi:10.1029/2006GL028260, 2007.

Wiedensohler, A., Cheng, Y. F., Nowak, A., Wehner, B., Achtert, P., Berghof, M., Birmili, W., Wu, Z. J., Hu, M., Zhu, T., Takegawa, N., Kita, K., Kondo, Y., Lou, S. R., Hofzumahaus, A., Holland, F., Wahner, A., Gunthe, S. S., Rose, D., Su, H., and Pöschl, U.: Rapid aerosol particle growth and increase of cloud condensation nucleus activity by secondary aerosol formation and condensation: A case study for regional air pollution in northeastern China, J. Geophys. Res.-Atmos., 114, D00G08, doi:10.1029/2008JD010884, 2009.

Zhou, J. C., Swietlicki, E., Hansson, H. C., and Artaxo, P.: Submicrometer aerosol particle size distribution and hygroscopic growth measured in the Amazon rain forest during the wet season, J. Geophys. Res.-Atmos., 107(D20), 8055, doi:10.1029/2000JD000203, 2002. 